\title{
Princípios epistemológicos da teoria do capital social na área da administração
}

\author{
Epistemological principles of the social capital theory in the management field
}

\author{
Paulo Thiago Nunes Bezerra de Melo ${ }^{1}$ \\ Helder Pontes Regis ${ }^{2}$ \\ Hans Michael van Bellen ${ }^{3}$
}

\begin{abstract}
Resumo
Este artigo tem o objetivo de apresentar uma classificação paradigmática das referências predominantes sobre a teoria do capital social na ciência da administração a partir da identificação dos princípios epistemológicos subjacentes. Os cientistas sociais têm oferecido uma variedade de definições de capital social, nas quais cada uma expressa uma particularidade significante. Subjacente a esse fato estão os princípios epistemológicos que têm sido utilizados para guiar os investigadores em suas pesquisas, que refletem uma visão de mundo que é anterior aos conceitos que estão tentando definir. Neste artigo, a análise epistemológica é guiada buscando identificar elementos do empirismo, do racionalismo, do utilitarismo, do positivismo, do funcionalismo, do sistemismo e da dialética. São analisadas as contribuições de Bourdieu, Coleman, Putnam, Fukuyama e Ghoshal sobre a teoria do capital social. As análises são apresentadas considerando a área de especialização dos autores, seja a sociologia, a ciência política ou a administração. De maneira geral, pode-se concluir que os princípios do sistemismo são predominantes nas concepções de capital social elaboradas pelos autores analisados. As abordagens de Coleman, Putnam, Fukuyama e Ghoshal podem ser classificadas como desenvolvidas em um paradigma funcionalista, enquanto a abordagem de Bourdieu pode ser posicionada em um paradigma crítico.
\end{abstract}

Palavras-chave: Capital Social. Princípios Epistemológicos. Administração.

\begin{abstract}
This article aims to present a paradigmatic classification of the predominant references on the social capital theory in management science from the identification of the underlying epistemological principles. Social scientists have offered a variety of definitions of social capital, in which each one expresses a significant particularity. Underlying this fact, scientists have used epistemological principles in their research, which reflect a worldview that is prior to the concepts they are trying to define. In this article, the epistemological analysis seeks to identify elements of empiricism, rationalism, utilitarianism, positivism, functionalism, systemism and dialectics. We analyse the contributions of Bourdieu, Coleman, Putnam, Fukuyama and Ghoshal on the social capital theory. The analyses are presented considering the area of
\end{abstract}

Artigo submetido em 16 de junho de 2014 e aceito para publicação em 30 de setembro de 2014.

\section{DOI: http://dx.doi.org/10.1590/1679-395125382}

1 Doutorando em administração pela Universidade Federal de Santa Catarina; Professor da Universidade Federal Rural de Pernambuco. Endereço: Universidade Federal Rural de Pernambuco, Unidade Acadêmica de Serra Talhada (UAST), Avenida Padre Cícero, Bomba, CEP 56909-460, Serra Talhada - PE, Brasil. E-mail: pthiagoadm@hotmail.com

2 Doutor em administração pela Universidade Federal de Pernambuco; Professor da Universidade Federal Rural de Pernambuco. Endereço: Universidade Federal Rural de Pernambuco, Conselho Universitário, Campus Recife - Dois Irmãos, Av. Dom Manoel de Medeiros, SN, Dois Irmãos, CEP 52171-900, Recife - PE, Brasil. E-mail: hregis@hotlink.com.br

3 Doutor em engenharia de produção pela Universidade Federal de Santa Catarina; Professor adjunto da Universidade Federal de Santa Catarina. Endereço: Universidade Federal de Santa Catarina, Centro Tecnológico, Departamento de Engenharia do Conhecimento, Caixa-postal 476, Trindade, CEP 88040-900, Florianópolis - SC, Brasil. E-mail: hansmichael.vanbellen@gmail.com 
expertise of the authors, being sociology, political science or management. In general, we conclude that the principles of systemism are prevalent in the concepts of social capital developed by the authors analysed. The approaches of Coleman, Putnam, Fukuyama and Ghoshal can be classified as developed in a functionalist paradigm, while Bourdieu's approach can be positioned in a critical paradigm.

Keywords: Social Capital. Epistemological Principles. Management.

\section{Introdução}

O avanço científico certamente elucida os pontos que são questionados pela sociedade, bem como torna mais compreensíveis os fenômenos que ocorrem no mundo. Contudo, o conhecimento científico não é neutro, sendo ele construído com base em diversos princípios que, por vezes, podem resultar em explicações concordantes ou concorrentes para um mesmo fenômeno. O estudo do conjunto de princípios com base nos quais o conhecimento se desenvolve é domínio da epistemologia. Os princípios epistemológicos que dão base às diversas teorias são utilizados pelos pesquisadores diferentemente em um contexto histórico. Assim, um mesmo fenômeno é visto de maneiras diferentes entre diferentes pesquisadores se eles utilizam princípios diferentes em suas concepções.

Nessa discussão, a análise epistemológica tem a importância de revelar os princípios que regem um determinado domínio teórico, permitindo avaliar a coerência teórica em relação aos objetivos nos trabalhos científicos. Ao longo do desenvolvimento da ciência da administração, o ciclo hegemônico do paradigma funcionalista pode ser visto nos estudos organizacionais. Contudo, em uma tentativa cada vez maior de procurar explicar fenômenos que não são facilmente observados, os cientistas organizacionais têm avançado sobre objetos de estudo nos quais os princípios positivistas e funcionalistas podem não ser suficientes. No início do século XXI, os cientistas sociais intensificaram os estudos sobre temas que permitem compreender a dinâmica da vida organizacional no contexto contemporâneo, estando, entre eles, os estudos sobre capital social. Neste artigo, a análise epistemológica fornece suporte para maior compreensão dos princípios que guiam os arcabouços conceituais sobre o domínio específico do "capital social", com base em autores predominantes nas referências a esse tema na produção científica brasileira da área da administração.

Os cientistas sociais têm oferecido uma variedade de definições de capital social, nas quais cada uma expressa uma particularidade significante (ADLER e KWON, 2002). No entanto, há um consenso geral de que o capital social se refere às habilidades dos atores em garantir benefícios por meio da integração em redes sociais ou em outras estruturas sociais, apesar das diferenças conceituais encontradas quando se compara as definições dos investigadores do tema (PORTES, 1998). Subjacentes a esse fato estão os princípios epistemológicos que têm sido utilizados para guiar os investigadores em suas pesquisas, que refletem uma visão de mundo que é anterior aos conceitos que estão tentando definir.

Este artigo tem o objetivo de apresentar uma classificação paradigmática das referências predominantes sobre a teoria do capital social na ciência da administração a partir da identificação dos princípios epistemológicos subjacentes. A seguir, são apresentados os princípios básicos das correntes epistemológicas que influenciam a ciência da administração; as discussões epistemológicas específicas da administração; a teoria do capital social como domínio específico de investigação; e as análises epistemológicas de suas referências. Ao final do texto, são apresentadas as conclusões alcançadas por essa análise particular.

\section{Correntes Epistemológicas}

Quando se trata do conceito de epistemologia, Japiassu (1991, p. 25) define o termo como o "estudo crítico dos princípios, das hipóteses e dos resultados das diversas ciências". O objetivo da epistemologia é determinar a origem lógica das ciências, considerando seu valor e seu alcance (JAPIASSU, 1991). Existe um 
ciclo hegemônico de um paradigma científico dominante - que é o da ciência moderna - como aquele que origina os modelos de racionalidade presentes nas ciências naturais e, posteriormente, é estendido às ciências sociais, resultando em um modelo global de racionalidade científica (SOUZA-SANTOS, 1988). Esse paradigma dominante rejeita qualquer conhecimento de senso comum, fazendo a distinção do conhecimento científico. Souza-Santos (1988) especula as características de um paradigma emergente que reconhece, sobretudo, a importância do senso comum na racionalidade científica, que seria a ciência pós-moderna. Portanto, o conhecimento científico pode ser pressuposto como um conjunto de ideias que nunca se completa na tentativa de explicar como o mundo e os elementos que o constituem funcionam. Neste artigo, a análise epistemológica é guiada buscando identificar elementos do empirismo, do racionalismo, do utilitarismo, do positivismo, do funcionalismo, do sistemismo e da dialética.

Como referência do empirismo, Bacon (1979) propõe que as pessoas devam se habituar à complexidade das coisas como elas são observadas pela experiência. Para Bacon (1979), a ciência precisa ser demonstrada rigorosamente pela investigação de experimentos. Em sua concepção, apenas as coisas que podem ser definidas merecem ser investigadas pela classificação, verificação, pesagem e mensuração. Ele ressaltou a importância de registrar de maneira sistemática todos os fatos observáveis em um objeto investigado e de interpretar tais fatos pela orientação da indução.

Como referência do racionalismo, Descartes (1979) defendia a existência de uma ciência alcançada por juízos puros e sólidos por meio da razão. Ele ressaltava a importância de examinar os princípios e fundamentos de um conhecimento para julgar a sua veracidade, desfazendo-se das opiniões e duvidando dos princípios que se dava crédito. Descartes (1979) dedicou-se a estabelecer um método que julgava ser o verdadeiro para se chegar ao conhecimento de todas as coisas. Esse método é composto de quatro preceitos que deviam ser seguidos estritamente: jamais presumir a veracidade das coisas sem antes examinar evidências; dividir as dificuldades da investigação em partes; ordenar o pensamento a partir das coisas mais simples para as mais complexas, mesmo quando uma ordenação não se precede naturalmente; fazer enumerações e revisões completas e gerais. Para Descartes (1979), uma razão certa e evidente precisa ser demonstrada invariavelmente por meio da dedução e haveria apenas uma verdade de cada coisa.

Existem semelhanças no posicionamento de Bacon (1979) e de Descartes (1979). Ambos os filósofos são reconhecidos frequentemente como precursores da ciência moderna. As abordagens que eles propõem no desenvolvimento do conhecimento científico foram uma contribuição acerca de um modelo de racionalidade, sobretudo dos avanços específicos alcançados com a utilização dos métodos postulados por eles. Por outro lado, não se pode negar que a dominação hegemônica desse paradigma foi necessária para a evidenciação formal das leis da natureza (SOUZA-SANTOS, 1988).

Outro ponto que deve ser observado é o contexto histórico de onde essa racionalidade emergiu e que o manteve, ou mantém, hegemônico ao longo do tempo, como a fonte principal de conhecimento de uma sociedade. A ciência moderna surgiu em contraponto ao conhecimento difundido pela igreja, com pressupostos dogmáticos e pretensões alienadoras. Assim, os fenômenos da natureza eram explicados como eventos da vontade de uma divindade, seja para recompensar ou para punir o comportamento dos indivíduos. A ciência moderna aparece nesse contexto como uma alternativa para se pensar nos fenômenos da natureza e, posteriormente, nos fatos sociais.

Apesar das limitações já sabidas inerentes ao modelo de racionalidade da ciência moderna, esse paradigma contribuiu substancialmente para a liberdade substantiva dos indivíduos que tomaram os conhecimentos gerados nele como verdadeiros, uma vez que "desalienava" o sujeito da dominação da igreja. Portanto, é possível dizer que a ciência moderna teve sua origem na contestação com relação às orientações religiosas que dominavam a forma de viver e o senso comum da época. Mas, se por um lado, a ciência moderna libertou a sociedade da alienação religiosa, por outro lado, ela a aprisionou em uma visão "coisificada" de mundo, onde qualquer pensamento provido de subjetividade era rejeitado como conhecimento científico, mesmo que esses pensamentos não tivessem orientação religiosa. 
Como referência do utilitarismo, Bentham (1979) discute a concepção do princípio da utilidade. Ele aborda o assunto ressaltando a importância da dor e do prazer como influências na tomada de decisões dos indivíduos. Em seguida, ele estabelece que o princípio da utilidade "consiste em construir o edifício da felicidade através da razão e da lei". A aprovação ou desaprovação de qualquer ação é baseada na tendência que esta tem de aumentar ou diminuir a felicidade das pessoas, na mesma intensidade do prazer ou dor provocada; ou seja, é baseada no princípio da utilidade. Bentham (1979) estabeleceu que o princípio da utilidade fosse o início de uma cadeia de demonstrações, e que, por isso, não podia ele próprio ser demonstrado.

A demonstração se constitui um fator importante no positivismo, como mostrado por Padovani e Castagnola (1990). Eles afirmam que o positivismo se limita "à experiência imediata, pura, sensível, como já fizera o empirismo" ao comparar com a visão mais ampla do idealismo. O positivismo surge com o progresso das ciências naturais, considerando a experiência, os fatos postos e os dados sensíveis como as únicas fontes de conhecimento e verdade, rejeitando a metafísica. Para esses autores, o positivismo originou as concepções utilitárias, como mostradas por Bentham (1979), bem como os sistemas político-econômico-sociais que delas dependem, como a democracia moderna, o liberalismo e o socialismo.

Pedro Demo (1985) aprofunda a discussão sobre o positivismo mostrando como as questões do empirismo estão associadas às questões teóricas. Para ele, a pesquisa se constrói na confluência do esforço teórico e do esforço empírico. Por outro lado, ele também reconhece a existência da pesquisa exclusivamente teórica. Ainda assim, ele afirma que a base empírica é essencial para a demarcação científica das teorias, mesmo que seja pela sua falsificação em vez de verificação. Dortier (2000) esclarece que o avanço do conhecimento só pode acontecer pela ciência baseada na demonstração rigorosa dos fatos observáveis. Para os positivistas, as proposições baseadas em fatos têm sentido e são passíveis de serem verificadas, ao contrário das proposições metafísicas. Contudo, Schlick (1980) afirma que a ciência empírica é capaz de acessar apenas o lado aparente e superficial do conhecimento. Para esse autor, um dos conceitos básicos do positivismo é se limitar ao dado, e somente este é real, rejeitando a metafísica e qualquer realidade transcendente. Popper (1980) discute o método utilizado nas ciências empíricas, ou seja, o método de indução, considerando que tal método consiste na formulação de enunciados universais como hipóteses ou teorias, a partir de um conjunto de enunciados singulares de observações ou experimentos.

Com relação à previsibilidade do futuro do método indutivo próprio do empirismo, Demo (1985) apontava que a tentativa de universalização do conhecimento fica frustrada, uma vez que não se pode pressupor que o conhecimento concebido empiricamente hoje será sempre corroborado no futuro. Essa crítica se torna mais intensa especialmente quando se trata das investigações sociais. Nesse tipo de pesquisa, assim como nas demais, o empirismo é um método eficiente para o entendimento de fatos, mas que não se pode esperar que ele se repita incessantemente. Uma crítica bastante recorrente ao empirismo e ao positivismo é a tentativa de generalizar um conhecimento de maneira superficial, que, supostamente, não contém juízo de valor, que poderia ser desvendado igualmente por qualquer um que reproduzisse o procedimento realizado. Contudo, esse ponto é crítico mais uma vez, especialmente nas pesquisas sociais, devido aos diferentes significados que um mesmo dado pode representar para cada pessoa que o observa, e mais do que isso, para a mesma pessoa que o observa em momentos diferentes. Mesmo nas ciências naturais, o juízo de valores é feito pelo pesquisador ao escolher e justificar o método e o propósito da pesquisa. Portanto, apesar de as ciências sociais terem acumulado um conjunto de "verdades" que partem de investigações positivistas, a irrefutabilidade dos resultados não pode ser alcançada em pesquisas sociais, mesmo tomando todas as precauções devidas ao positivismo.

Se, por um lado, é certo que o progresso nas ciências naturais deve muito ao empirismo, por outro lado, é questionável como, de fato, essa forma de gerar conhecimento tem contribuído para as ciências sociais. Decerto que as combinações e os testes de elementos químicos e físicos em laboratórios sob condições controladas podem ser realizados e repetidos inúmeras vezes, bastando que os materiais e o ambiente estejam disponíveis. Contudo, em uma pesquisa social, o objeto de estudo está em constante transformação, sendo cada observação sempre única e exclusiva. É possível ilustrar essa ideia com o pensamento de Heráclito de 
Éfeso: "Não se pode percorrer duas vezes o mesmo rio e não se pode tocar duas vezes uma substância mortal no mesmo estado".

O funcionalismo surge para as ciências sociais como uma tentativa de observar e de analisar o que acontece na sociedade, tal como as ciências naturais tratam as leis da natureza, dando origem a abordagens específicas, como a sociologia e a antropologia social. De certa maneira, tratar a sociedade como um objeto de estudo semelhante aos fenômenos da natureza e aplicar naquela os métodos utilizados para estudar estes contribuem para o entendimento dos eventos regulares e padronizados em um determinado momento no tempo. Os princípios funcionalistas permitem analisar eventos regulares e padronizados na sociedade que dificilmente seria possível de outra maneira. Durkheim (1978) é uma referência do funcionalismo ao considerar que os fatos sociais são constituídos pelas crenças, tendências e pelas práticas do grupo tomadas coletivamente.

Malinowski (1970) conceitua o funcionalismo como um método de compreensão da natureza e dos fenômenos culturais sem fazer uso de manipulações especulativas, considerando as relações e os vínculos essenciais, indo além dos fatos isolados. Para ele, a cultura é composta por vários elementos interdependentes que realizam tarefas importantes, onde cada parte existe como um meio para um fim. Radcliffe-Brown (1973) afirma que a função de um costume social é a contribuição que ele oferece ao funcionamento do sistema social total, considerando que os costumes sociais podem ter funções diferentes em duas sociedades diferentes. Segundo Evans-Pritchard (1972), os antropólogos sociais pressupõem que a vida social pode ser submetida a previsões, uma vez que seja reduzida às leis científicas, tal como nos sistemas naturais compostos por partes interdependentes que satisfazem uma necessidade específica para a manutenção do sistema total. Selznick (1967) afirma que as organizações vistas pelos princípios funcionais são caracterizadas pelos seus aspectos mais gerais ou como uma economia. Para ele, de acordo com os princípios funcionais, as organizações devem ser vistas como sistemas cooperativos.

Uma reflexão que pode ser feita é que os princípios funcionalistas só permitem que a parte visível do iceberg - sendo o iceberg os sistemas sociais - possa ser observada, que se referem aos eventos superficiais, regulares e padrões. Portanto, a maior parte dos sistemas sociais, aquela representada pela parte submersa de um iceberg, não é possível de ser observada e compreendida pelos princípios funcionalistas; já princípios que permitam avaliar as idiossincrasias contidas nas relações entre os indivíduos precisam ser considerados. Uma vez que estes princípios sejam considerados, cada investigador que os utiliza é capaz de se aprofundar no entendimento dos sistemas sociais com uma visão particular e única, assim como um mergulhador que vai ao fundo do mar para observar a parte submersa de um iceberg. Outra reflexão que merece ser considerada é sobre como os sistemas sociais se concretizaram ao longo do tempo na forma como eles são observados em um determinado momento. Para entender como os sistemas sociais se constituem, é necessário considerar uma perspectiva histórica, que o funcionalismo rejeita. A perspectiva histórica permite revelar que os sistemas sociais podem ser constituídos por eventos de ruptura, bem como por meio de eventos regulares ao longo do tempo. A perspectiva histórica também permite revelar com maior detalhe como os sistemas sociais se destroem, ou como eles tentam se adaptar a mudanças repentinas e bruscas no ambiente em que estão presentes.

De acordo com Demo (1985), o sistemismo é uma continuidade do funcionalismo. Demo (1985) considera a ideia de que todo sistema pode ser um subsistema de um sistema maior, de forma que o modo como os elementos de um sistema estão organizados é que delimita cada sistema. Ele ressalta que a organização dos elementos de um sistema é o fator que faz com que o todo constituído pelo sistema seja maior do que o resultado da soma dos elementos se estes estiverem isolados ou desorganizados. Parsons (1967) distingue uma organização dos outros tipos de sistemas sociais pelo fato de ela buscar a consecução de uma meta específica, produzindo algo que é utilizado por outro sistema. Para Buckley (1971), o que permite a comparação da sociedade como sistema a um organismo, ou o modelo orgânico, é a interdependência das partes. Esse autor afirma que todo sistema tenderia a estar sempre em uma situação estática, sendo qualquer mudança considerada como um problema ou um evento irregular causado por alguma força exógena. Ele também considera que os elementos de um sistema competem em uma visão evolucionista. Rosenweig e 
Kast (1980) afirmam que os sistemas sociais, bem como os biológicos, são sistemas abertos que se comunicam com o ambiente externo. Segundo esses autores, as teorias modernas consideram que as organizações são capazes de alcançar uma estabilidade dinâmica, ou entropia negativa, por meio de seu ajustamento constante com o ambiente externo.

O enfoque sistêmico, de certa forma, agrega uma riqueza de possibilidades de análise aos princípios funcionalistas. Uma vez que se reconhece que os eventos sociais são sistêmicos e que existem forças externas que influenciam a manutenção dos sistemas sociais é um avanço que permite se ter uma visão mais ampla da sociedade. Apesar do relativo avanço, os princípios funcionalistas continuam presentes no enfoque sistêmico, de modo que este não deve ser considerado uma corrente que rompe com as tradições das investigações positivistas. E é exatamente por isso que, mesmo com os avanços alcançados, o enfoque sistêmico sofre as mesmas críticas que são pertinentes aos princípios positivista e funcionalista.

Apesar do caráter evolucionista, o sistemismo não ressalta a presença de situações de conflitos entre subsistemas diferentes. Uma vez que um sistema maior é formado por subsistemas, essa composição não acontece sempre de maneira harmoniosa. A complementaridade entre os subsistemas pode se dar de maneira conflituosa, bastando que cada um tenha objetivos opostos ao outro. Assim, esse mesmo raciocínio pode ser aplicado aos vários níveis de observação dos sistemas, considerando as suas fronteiras. Portanto, a afirmação corrente de que um conjunto de subsistemas forma um sistema maior compreende uma dinâmica que envolve cooperação em alguns casos, mas conflitos em outros, com o foco de atenção nos objetivos que são buscados pelos sistemas.

Foulquié (1978) faz uma revisão sobre as ideias dos precursores da dialética como Heráclito de Éfeso e das ideias de Hegel e Marx. Para Gurvitch (1987), toda dialética visa entre as totalidades e a suas partes simultaneamente, devendo considerar os movimentos da pluralidade das totalidades e das suas unificações. Esse autor destaca que a dialética também é vista como método, que consiste na negação, destruindo a lógica formal com a finalidade de atingir o que esta não alcança. Uma vez que destrói os pensamentos cristalizados, a dialética também é vista como o abalo de qualquer estabilização aparente na sociedade por manifestar e enfatizar tensões, oposições, conflitos, lutas, contrários e contraditórios (GURVITCH, 1987). Lefebvre (1983) estabelece a distinção entre a lógica formal e a lógica dialética. Para ele, a lógica formal se preocupa em definir características gerais, classificar e agrupar elementos, negligenciando o conteúdo e a verdade de uma afirmação, enquanto a dialética é o exame das interações entre os elementos opostos que fazem o conteúdo, estando ligada a uma concepção científica da história.

Demo (1985) destaca a historicidade como um elemento da dialética, o "vir a ser" contínuo das formações sociais, particularizando a qualidade de tudo ser provisório. Ele também explica que o contexto dialético é profundamente marcado pelo conceito de processo, considerando a condição de existência de que nada está completamente acabado, estando sempre em um processo de formação, seja como progresso ou como regresso. Benson (1987) desenvolveu uma concepção dialética nas teorias das organizações, considerando que estas estão sempre no caminho a ser algo como elemento da sociedade. Para ele, a ênfase da dialética é o processo de como a organização é criada, os mecanismos que as mantêm e a continuidade e reconstrução delas como instrumentos de dominação nas sociedades industriais avançadas.

Nas ciências, a dialética é o elemento capaz de ampliar as perspectivas de uma determinada abordagem, com a intenção de superar os limites que se impõem à lógica formal. A dialética é um recurso de desenvolvimento de ideias que vai além do que é científico, sendo utilizado até mesmo como exercício mental em algumas comunidades religiosas orientais. Ao mostrar contradições, a dialética possui o propósito de revelar as contradições inerentes ao mundo real. Os defensores da dialética costumam afirmar que está implícita na lógica formal a predileção pela manutenção dos sistemas sociais estabelecidos sob relações de dominação e de alienação.

Uma elaboração realizada por Barcellos e Dellagnelo (2013) adaptada para contemplar a corrente do sistemismo destaca os conceitos centrais das correntes epistemológicas discutidas neste artigo (quadro 1). 
Quadro 1

Correntes epistemológicas e conceitos centrais

\begin{tabular}{|c|c|}
\hline $\begin{array}{l}\text { Corrente } \\
\text { epistemológica }\end{array}$ & Conceito central \\
\hline Empirismo & $\begin{array}{l}\text { Só é real aquilo que pode ser experimentado e a ciência se constitui, assim, na } \\
\text { capacidade de repetir estes experimentos, a fim de conhecer a natureza. }\end{array}$ \\
\hline Racionalismo & $\begin{array}{l}\text { Sem refutar o empirismo, destaca a importância da razão humana para o processo de } \\
\text { construção do conhecimento científico, já que este não poderia se realizar senão por } \\
\text { intermédio e intervenção do cientista. }\end{array}$ \\
\hline Utilitarismo & $\begin{array}{l}\text { O princípio da utilidade consiste em maximizar o prazer e/ou minimizar a dor. A } \\
\text { utilidade constitui a única razão que explica porque uma determinada ação pode ou } \\
\text { deve ser praticada. }\end{array}$ \\
\hline Positivismo & $\begin{array}{l}\text { A única fonte de conhecimentos e critérios de verdade é a experiência, os dados } \\
\text { positivos, os dados sensíveis. }\end{array}$ \\
\hline Funcionalismo & $\begin{array}{l}\text { A função significa a satisfação de uma necessidade, é a parte que um indivíduo } \\
\text { desempenha na vida social como um todo e, portanto, a contribuição que faz para a } \\
\text { manutenção da continuidade estrutural. }\end{array}$ \\
\hline Sistemismo & $\begin{array}{l}\text { Continuidade do funcionalismo que ressalta a organização dos elementos de um sistema } \\
\text { ou de um conjunto de sistemas como principal fator para a satisfação de objetivos. }\end{array}$ \\
\hline Dialética & $\begin{array}{l}\text { Interdependência entre as partes; o real é contraditório; o movimento e o devir são } \\
\text { criadores de algo novo. }\end{array}$ \\
\hline
\end{tabular}

Fonte: Adaptado de Barcellos e Dellagnelo (2013).

Uma vez pontuadas as características principais do empirismo, do racionalismo, do utilitarismo, do funcionalismo, do sistemismo e da dialética, é possível apresentar a seguir uma discussão sobre a epistemologia específica da ciência da administração.

\section{Epistemologia da ciência da administração}

A administração está ligada ao advento da sociedade moderna, e a ausência de uma reflexão epistemológica na ciência da administração faz com que esta seja construída sobre o parasitismo ideológico, o normativismo e o empirismo (CHEVALLIER e LOSCHAK, 1980). Os pesquisadores da organização científica do trabalho, seguidores de Taylor, não se preocupavam com a cientificidade de suas produções, nem com o movimento da epistemologia geral da época. O período da Segunda Guerra Mundial representou o surgimento de dimensões criadoras de ordem importantes para as ciências da administração, como o governo, a coordenação e o controle, dentro de uma epistemologia normativa de uma corrente dominante àquela época. Na década de 1970, uma diversidade epistemológica surge com inspiração na historiografia e na sociologia, sendo puxada por pesquisadores das áreas da sociologia, ciência política e antropologia. Desde a década de 1980, a partir dos conceitos e das estratégias de pesquisa da epistemologia da organização, começa a haver uma "reconceitualização" dos objetos de estudo do campo das ciências da administração (AUDET e DÉRY, 1996). 
Ao discorrer sobre a dominância e a emergência de paradigmas nos estudos organizacionais, Chanlat e Séguin (1987) propõem uma série de concepções para as organizações, associando elas a um paradigma funcionalista ou a um paradigma crítico de acordo com o quadro 2.

Quadro 2

\section{Elementos dos paradigmas funcionalista e crítico}

\section{PARADIGMA FUNCIONALISTA}

Sistêmica: conjunto de partes relacionadas umas às outras, onde esforços coordenados atingem resultados maiores do que a soma dos esforços individuais;

Teleológica: a noção de objetivos e metas é uma dimensão central que embasa a racionalidade organizacional, servindo de medida para a avaliação de eficácia;

Não histórica: forte ocultamento e marginalização dos fenômenos de causalidade e de mudança ao longo do tempo nas organizações;

Integradora: a organização é composta por indivíduos e grupos em harmonia, com objetivos comuns aceitos por todos.

\section{PARADIGMA CRÍTICO}

Sociológica: as relações que as organizações desenvolvem internamente e externamente dependem das ideologias, valores e concepções de mundo na estrutura social própria de uma determinada sociedade;

Histórica: as organizações e as relações sociais se formam e se modificam ao longo do tempo, desvendando crises e transformações na sociedade da qual elas fazem parte;

Dialética: as organizações são permeadas por conflitos, crises e contradições nos quais são revelados seus processos;

Desmistificadora: denuncia os mitos legitimados pelos trabalhos que têm o objetivo de melhor controlar a mão de obra nas organizações;

Acionalista: as organizações nascem, se transformam, desaparecem e renascem como produtos da ação humana;

Emancipatória: libertação dos indivíduos em relação aos limites que justificam a dominação e a exploração, buscando a realização de maior humanização nas organizações.

Fonte: Adaptado de Chanlat e Séguin (1987).

No Brasil, a epistemologia da administração é tratada na reflexão do sociólogo Guerreiro Ramos (1989) sobre a abordagem substantiva das organizações. Guerreiro Ramos (1989) revela quatro aspectos que tornam a teoria da organização desenvolvida até a década de 1980 em uma abordagem reducionista dos sistemas sociais. Primeiro, a natureza humana é associada apenas ao comportamento econômico, visando à realização de objetivos e fins a partir de uma racionalidade instrumental; segundo, todas as formas de organizações são tratadas como organizações econômicas e formais; terceiro, o papel da interação simbólica normalmente não é compreendido; e quarto, a distinção entre trabalho e ocupação não é considerada.

Em contraponto à abordagem instrumental da organização, Guerreiro Ramos (1989) propõe a abordagem substantiva, que requer a consideração da natureza ética na realização dos objetivos, indo além da racionalidade instrumental; o reconhecimento de organizações não mercantis ou não formais nas sociedades; a compreensão da interação simbólica como uma atividade que dá sentido à existência dos indivíduos; e a distinção entre trabalho e ocupação, sendo o primeiro um esforço subordinado às necessidades do processo produtivo e o segundo um esforço realizado livremente em busca de atualização pessoal. 
No início da década de 1990, a epistemologia da administração é tratada no Brasil na reflexão apresentada por Anna Maria Campos (1997) em um seminário de administração pública realizado pela Fundação Oswaldo Cruz que discutia os desafios do Sistema Único de Saúde. Essa autora destacou que as teorias da administração foram desenvolvidas em um paradigma dominante nas ciências, que é marcado por limitações decorrentes da visão mecanicista do universo como o reducionismo, a incompetência para lidar com as contradições e a não apreciação da subjetividade (CAMPOS, 1997).

No ano 2000, a Associação Nacional de Pós-graduação e Pesquisa em Administração realizou o primeiro Encontro de Estudos Organizacionais em seu âmbito, no qual Garcia e Bronzo (2000) apresentaram uma reflexão sobre as bases epistemológicas do pensamento administrativo. Esses autores iniciam sua reflexão ressaltando que os processos científicos não são desinteressados e descolados da prática social, de forma que as teorias organizacionais foram desenvolvidas refletindo a subordinação da ciência ao capital e aos interesses dominantes. De acordo com Garcia e Bronzo (2000), os problemas da prática administrativa são mais coerentemente explicados quando diferentes perspectivas teóricas são confrontadas por meio da análise dos estudos organizacionais em perspectiva histórica, com base na dialética. Esses autores também afirmam que os desafios da prática administrativa, como as relações de poder e dominação, não foram compreendidos nas escolas convencionais de pensamento da administração, pois o principal elemento da organização em suas elaborações é a eficiência interna, sendo os conflitos tratados como anomalias que devem ser sanadas para restabelecer a ordem dominante.

A contribuição de Garcia e Bronzo (2000) para a epistemologia da administração no Brasil representa uma das reflexões com maior profundidade nos últimos anos (SERVA, 2013). De acordo com Serva (2013), o interesse na epistemologia da administração no Brasil é cada vez maior, sendo refletido na adoção de disciplinas específicas nos currículos de programas de mestrado e doutorado, na instituição do tema no âmbito da Associação Nacional de Pós-graduação e Pesquisa em Administração desde 2009, e na realização do Colóquio Internacional da Epistemologia e Sociologia da Ciência da Administração pela Universidade Federal de Santa Catarina desde 2011. O desenvolvimento da epistemologia da administração abriu diferentes caminhos de análise que discutem questões de método, de validade da produção científica e das condições sociais dessa produção, analisando o campo da área geral ou de suas subáreas específicas (SERVA, 2013). As possibilidades de contribuição da epistemologia da administração para o aperfeiçoamento da teoria administrativa são indicadas por Serva (2013) como: o amadurecimento do campo enquanto conhecimento científico pela atitude de reflexão, compreensão dos pressupostos e melhoria dos protocolos que apoiam as pesquisas; a aproximação entre teoria e prática por abrir o diálogo entre os produtores de conhecimentos; a demonstração da natureza dos interesses dos atores no campo; o aperfeiçoamento do ensino da disciplina; e a compreensão ampla do conjunto da ciência da administração.

O desenvolvimento recente da epistemologia da administração no Brasil tem sido impulsionado pela criação de espaços dedicados a esse tipo de discussão, conforme é destacado por Serva (2013). Esses novos espaços têm permitido discussões sobre a ciência da administração de maneira geral e sobre as suas subáreas, mas também têm permitido o surgimento de discussões sobre domínios específicos associados à prática administrativa contemporânea. Entre os estudos sobre análise epistemológica de domínios específicos que têm sido publicados, o estudo Barcellos e Dellagnelo (2013) merece ser mencionado por apresentar uma discussão ampla sobre as principais correntes epistemológicas, que serviu como base para analisar as referências mais utilizadas no Brasil sobre o domínio específico da responsabilidade social corporativa. De maneira semelhante, esse estudo analisa as referências mais utilizadas no Brasil sobre o domínio específico do capital social na ciência da administração.

\section{Capital Social}

Inicialmente, a compreensão sobre a natureza do capital e seus desdobramentos pode facilitar a compreensão do que é o capital social e qual é a sua posição nas explicações das dinâmicas socioeconômicas. A teoria 
clássica do capital, difundida por Marx (1984), mostrou que a comercialização de uma mercadoria gera um ganho excessivo para os proprietários dos meios de produção, ganho esse que é derivado do trabalho excedente em relação ao valor investido na produção da mercadoria, conceituando o valor de trabalho excedente de mais-valia. Na análise de Marx (1984), a mais-valia é a fonte de capital, que gera outra maisvalia, que gera mais capital em um ciclo de acumulação de capital (HUNT, 1985). Corroborando essa visão, Bourdieu (1986) afirma que o capital é o trabalho acumulado de maneira materializada que permite aos agentes privados se apropriar do trabalho vivo, sendo uma capacidade potencial para produzir e reproduzir lucros pela acumulação ao longo do tempo. Lin (1999) esclarece que a teoria clássica do capital é baseada na exploração das relações sociais entre a classe dominante, que faz investimento e obtém os ganhos excessivos, e a classe proletária, que vende sua força de trabalho e é explorada (LIN, 1999). Nessa perspectiva, a classe dominante reproduz o capital e se mantém na situação de dominante ao longo do tempo, enquanto a classe trabalhadora é explorada sem possibilidade de mobilização social.

A teoria clássica do capital recebe críticas dos pensadores da escola austríaca da economia, dentre os quais, Ludwig Lachmann (1978) desenvolveu a discussão sobre a estrutura do capital, que é utilizada atualmente como base teórica por outros pensadores austríacos (FOSS, FOSS, KLEIN et al., 2007; LEWIN e BAETJER, 2011; FOSS, 2012). Os economistas clássicos tornam o estoque de capital homogêneo por meio da mensuração dos bens em unidades de valor de trabalho, simplificando a sua diversidade (LACHMANN, 1978). O capital, no conceito de Lachmann (1978), é uma estrutura complexa composta por diversos recursos que têm funções diferentes.

Os recursos de capital não são meros meios de produção, mas são recursos utilizados pelas pessoas, sendo os seus múltiplos usos a representação da heterogeneidade do capital (LACHMANN, 1978). Por exemplo, uma lâmina de aço é usada distintamente por um cozinheiro, por um barbeiro e por um médico. A heterogeneidade do capital se reflete em diferentes atributos percebidos subjetivamente pelos gestores. As ações empreendedoras dos gestores na combinação de recursos e na inovação levam à percepção subjetiva dos ativos de capital, criando ou descobrindo os seus atributos, que podem ser percebidos distintivamente em decorrência da subjetividade de diferentes gestores (FOSS, FOSS, KLEIN et al., 2007). Por exemplo, o cozinheiro percebe que um bisturi não tem a extensão e o peso necessários para cortar legumes rapidamente, o barbeiro percebe que uma faca não tem a empunhadura necessária para controlar o corte de cabelos e o médico percebe que uma tesoura não garante a precisão necessária de uma incisão cirúrgica no coração de um paciente.

Em analogia às abordagens desenvolvidas na área da gestão estratégica para compreender as empresas, Lewin e Baetjer (2011) fornecem uma teorização sobre a visão da empresa baseada no capital, que compreende a empresa como uma estrutura de capital composta por recursos físicos e humanos, enfatizando a organização do conhecimento incorporado em tais recursos para realizar as tarefas necessárias à produção. Considerando a heterogeneidade do capital, os ativos incorporam capacidades específicas dos mercados, das empresas e dos trabalhadores, de forma que sua realocação de uma atividade para outra gera custos de transação, como os custos com pesquisa, averiguação e coordenação de novos ativos (FOSS, 2012). A relevância da teoria do capital da escola austríaca, segundo Foss (2012), repousa na sua compreensão do processo de crescimento econômico contemporâneo, que é positivamente relacionado à ação empreendedora.

De acordo com Lin (1999), os elementos centrais do capital, o ganho excessivo do capitalista e o investimento realizado com retornos esperados permaneceram nas modificações teóricas posteriores sobre capital humano (COLEMAN, 1988), capital cultural (BOURDIEU, 1986) e capital social, mas tais teorias provocam uma ruptura com a teoria clássica por permitirem a mobilidade de atores com menor estoque de capital financeiro, que se tornam capazes de realizar investimentos nessas formas de capital e obter ganhos superiores, sendo consideradas teorias do novo capital (LIN, 1999).

Um dos primeiros usos do termo "capital social" na literatura acadêmica foi feito por Hanifan (1916) quando trata de um centro comunitário rural no Estado da Virgínia Ocidental nos Estados Unidos. Nesse texto, o capital social é entendido como algo que pode satisfazer necessidades sociais para a melhoria substancial das 
condições de vida de toda uma comunidade, sendo direcionado por líderes habilidosos. O capital social surge em uma comunidade a partir da aproximação dos membros em razão de propósitos comuns a todos, que, ocasionalmente, leva a discussões construtivas sobre os problemas da comunidade e resultam em ações efetivas (HANIFAN, 1916). Posteriormente, Jane Jacobs (2009) reporta-se ao termo capital social no livro The death and life of great american cities, que foi publicado originalmente em 1961. Jacobs (2009) enfatiza a resolução de problemas em uma comunidade, afirmando que a rede de relações construídas e acumuladas ao longo do tempo pela permanência de certas pessoas em um bairro é o capital social necessário para a autogestão de um bom bairro. Outra citação do termo capital social é feita por Loury (1977) ao discutir sobre desigualdade racial, enfatizando o impacto da família e da comunidade na aquisição de habilidades requeridas no mercado por jovens negros. Nesse sentido, o capital social representa o grau em que o sucesso de um indivíduo no mercado é realizado por meio de forças sociais externas ao controle do indivíduo, uma vez que a quantidade de recurso que é investido na preparação desse indivíduo para o mercado é um efeito de sua origem social (LOURY, 1977).

Os cientistas sociais têm oferecido uma variedade de definições de capital social, nas quais cada uma expressa uma particularidade significante (ADLER e KWON, 2002). No entanto, há um consenso geral de que o capital social se refere às habilidades dos atores em garantir benefícios por meio da integração em redes sociais ou outras estruturas sociais, apesar das diferenças conceituais encontradas quando se compara as definições dos pesquisadores do tema (PORTES, 1998). O quadro 3 mostra um conjunto de conceitos para capital social com base nos autores mais predominantes no tema.

\section{Quadro 3}

\section{Conceitos de capital social}

\begin{tabular}{|l|l|}
\hline \multicolumn{1}{|c|}{ FONTE } & \multicolumn{1}{c|}{ CONCEITO } \\
\hline $\begin{array}{l}\text { Bourdieu (1980, p. } \\
\text { 2, tradução nossa) }\end{array}$ & $\begin{array}{l}\text { "o conjunto de recursos atuais ou potenciais que são colocados à posse de uma rede } \\
\text { durável de relações mais ou menos institucionalizadas pelo convívio e pelo } \\
\text { reconhecimento; ou, em outras palavras, ao pertencimento de um grupo, como um } \\
\text { conjunto de agentes que não são apenas dotados de propriedades comuns (suscetíveis de } \\
\text { serem percebidas pelo observador, por outros e por eles mesmos), mas são também } \\
\text { unidos por laços permanentes e úteis"; }\end{array}$ \\
\hline $\begin{array}{l}\text { Coleman (1988, p. } \\
\text { 98, tradução } \\
\text { nossa) }\end{array}$ & $\begin{array}{l}\text { "o capital social é definido por sua função. Ele não é uma entidade individual, mas uma } \\
\text { variedade de diferentes entidades com dois elementos comuns: todas elas consistem em } \\
\text { pessoas ou atores corporativos - dentro da estrutura"; }\end{array}$ \\
\hline $\begin{array}{l}\text { Putnam (2002, p. } \\
\text { 177) }\end{array}$ & $\begin{array}{l}\text { "características da organização social, como confiança, normas e sistemas, que } \\
\text { contribuam para aumentar a eficiência da sociedade, facilitando as ações coordenadas"; }\end{array}$ \\
\hline $\begin{array}{l}\text { Fukuyama (1996, } \\
\text { p. 41; 2000, p. 28) }\end{array}$ & $\begin{array}{l}\text { "uma capacidade que decorre da prevalência de confiança numa sociedade ou em certas } \\
\text { partes dessa sociedade"; "um conjunto de valores ou normas informais, comuns aos } \\
\text { membros de um grupo, que permitem a cooperação entre eles"; }\end{array}$ \\
\hline $\begin{array}{l}\text { Nahapiet e } \\
\text { Ghoshal (1998, p. } \\
\text { 243, tradução } \\
\text { nossa) }\end{array}$ & $\begin{array}{l}\text { "a soma de recursos atuais ou potenciais imersos nas, disponíveis pelas, e derivados das } \\
\text { redes de relacionamentos pertencentes a um indivíduo ou unidade social" }\end{array}$ \\
\hline
\end{tabular}

Fonte: Elaborado pelos autores. 
Ao discutir a emergência da ideia de capital social na sociologia moderna, Portes (1998) ressalta que os laços sociais podem ser úteis para controlar os comportamentos irregulares dos atores e fornecer o acesso a recursos, mas também podem restringir as liberdades individuais e bloquear atores externos aos mesmos recursos, por meio de preferências particulares. Após considerar uma série de controvérsias nas discussões contemporâneas, Lin (1999, p. 39, tradução nossa) conceitua o capital social como "o investimento dos indivíduos em relações sociais pelas quais eles ganham acesso aos recursos imersos para aumentar os retornos esperados de ações instrumentais ou expressivas". As ações instrumentais são tomadas para obter recursos que o ator ainda não possui, enquanto as ações expressivas são tomadas para manter os recursos que o ator já possui. As chances de obter recursos por meio de ações instrumentais são maiores em redes de relações caracterizadas pela abertura e pela presença de pontes, e a manutenção de recursos existentes por meio de ações expressivas é mais provável em redes mais densas com relações recíprocas entre os membros (LIN, 1999).

De maneira semelhante às outras formas de capital, o capital social é um ativo de longo prazo no qual se pode investir com expectativa de retorno futuro, pode ser apropriado e convertido em outras formas de capital, bem como pode substituir ou complementar outros recursos. Mas, diferentemente das outras formas de capital, o capital social precisa ser mantido e renovado, pode ser considerado um bem coletivo, localiza-se nas relações entre os atores e os investimentos para sua acumulação e não podem ser mensurados de maneira quantitativa (ADLER e KWON, 2002).

A partir de uma meta-análise do conceito de capital social, Fulkerson e Thompson (2008) afirmam que a diversidade de conceitos pode ser distinta em duas categorias: o capital social como recurso e o capital social normativo. Por um lado, o capital social normativo considera o conjunto de fatores na estrutura social que leva a ações coletivas para conseguir benefícios mútuos para um grupo de pessoas e consiste em uma explicação universal para padrões de desenvolvimento. Por outro lado, o capital social como recurso considera uma explicação para padrões desiguais de acumulação de poder, prestígio e outras formas de desigualdade, referindo-se a uma forma de investimento em redes de relacionamentos que traz retornos futuros. Os autores que defendem o capital social normativo enfatizam as transações recíprocas e agregação de valor na perspectiva da organização social, enquanto os autores que defendem o capital social como recurso enfatizam a confiança como obrigação e a racionalidade limitada. As discussões mais recentes levam uma tendência de alinhamento à ideia de capital social normativo (FULKERSON e THOMPSON, 2008).

Ao final dos anos 2000, a teoria do capital social parecia estar se tornando um paradigma na ampla comunidade de cientistas sociais, para além da sociologia (FULKERSON e THOMPSON, 2008). Na área de administração no Brasil, alguns pesquisadores têm se dedicado a investigar o capital social. Helal e Neves (2007) mostram que os indivíduos com maior estoque de capital social, por serem membros de organizações sociais, têm chances maiores de obter uma renda que lhe permita superar a linha de pobreza. Por outro lado, Rigo e Oliveira (2008) mostram que o capital social construído pela atuação de atores institucionais relevantes em uma comunidade caracterizada pela pobreza e com expectativas frustradas não é suficiente para mudar os comportamentos de acomodação e desesperança na comunidade. Serafim e Andion (2010) mostram que as estruturas sociais das organizações religiosas formam um tipo particular de capital social. Ducci e Teixeira (2011) mostram que as redes sociais de empreendedores permitem o acesso a diferentes recursos que influenciam na criação e no desenvolvimento dos negócios.

A seguir, são apresentadas as ideias acerca da teoria do capital social dos autores que têm sido utilizados constantemente como referências nos estudos na área da administração. Também são apresentadas as análises epistemológicas, buscando identificar os princípios das correntes destacadas no quadro 1, bem como realizar uma classificação paradigmática funcionalista ou crítica, conforme o quadro 2. As análises são apresentadas considerando a área de especialidade dos autores, seja a sociologia, a ciência política ou a administração. A sociologia tem discutido sobre capital social na perspectiva dos atores sociais e suas simbologias com base nas contribuições de Pierre Bourdieu e James Coleman. A ciência política tem discutido sobre capital social na perspectiva das nações e suas políticas, com base nas contribuições de 
Robert Putnam e Francis Fukuyama. A ciência da administração tem discutido sobre capital social na perspectiva das corporações e suas estruturas de relações com base na contribuição de Sumantra Ghoshal.

\section{Capital social na sociologia}

Nesta seção, são consideradas as contribuições de Pierre Bourdieu e James Coleman sobre a teoria do capital social. Pierre Bourdieu buscou construir instituições de produção científica protegidas das dependências do comando estatal e das regras de mercado. Em 1975, ele fundou a revista interdisciplinar Actes de la recherche en Sciences Sociales, que conduziu até sua morte em 2002, com a intenção de desnacionalizar a ciência social, quebrar as noções pré-construídas e romper com as formas estabelecidas da comunicação científica (WACQUANT, 2002).

Bourdieu abordou o tema capital social pela primeira vez em um artigo que abre a edição de novembro de 1979 do periódico Actes de la recherche en Sciences Sociales (BOURDIEU, 1979). Nessa ocasião, ele discutiu sobre outra forma de capital, o capital cultural, afirmando que o desempenho econômico e social que o título escolar pode trazer para um indivíduo depende do capital social herdado que pode ser usado por ele. Nesse texto, o autor não estabelece nenhum conceito ou definição sobre capital social, mas é possível identificar que sua concepção do tema envolve uma noção utilitarista, já que o capital social é visto por ele como um elemento que pode ser utilizado para satisfazer necessidades econômicas e sociais. Em 1980, Bourdieu escreveu uma nota de abertura da edição de janeiro do mesmo periódico tratando com mais profundidade suas ideias sobre capital social (BOURDIEU, 1980). Naquela ocasião, o capital social foi conceituado como "o conjunto de recursos atuais ou potenciais que são colocados à posse de uma rede durável de relações mais ou menos institucionalizadas pelo convívio e pelo reconhecimento; ou, em outras palavras, ao pertencimento de um grupo, como um conjunto de agentes que não são apenas dotados de propriedades comuns (suscetíveis de serem percebidas pelo observador, por outros e por eles mesmos), mas são também unidos por laços permanentes e úteis" (BOURDIEU, 1980, p. 2, tradução nossa).

Essa concepção de capital social guarda elementos centrais do sistemismo, pois considera que as redes de relações formam grupos de indivíduos ou partes de um determinado sistema, que, ao estarem conectados, são capazes de produzir resultados que, isoladamente, não seriam capazes. Trata-se da propriedade sinérgica dos sistemas. A presença do sistemismo na concepção de Bourdieu, por meio de sua característica sinérgica, também pode ser observada no seu tratamento sobre a identificação do volume de capital social que é possuído por um determinado indivíduo, afirmando que "depende da extensão da rede de conexões que ele pode efetivamente mobilizar e do volume de capital (econômico, cultural ou simbólico) possuído por cada um daqueles a quem ele estiver conectado" (BOURDIEU, 1980, p. 2, tradução nossa).

A predominância do sistemismo na concepção de Bourdieu sobre capital social é observável quando ele discute a manutenção e a reprodução do capital social nas estruturas sociais. Ele afirma que a reprodução e a manutenção do capital social pressupõem um esforço incessante de sociabilidade, ou seja, uma série contínua de trocas em que o reconhecimento é infinitamente afirmado e reafirmado, fornecendo ganhos proporcionais ao tamanho do capital (BOURDIEU, 1980). Essa discussão está suportada pela ideia de que os esforços individuais em relacionamentos sociais são o insumo para uma dinâmica que se realiza na estrutura social e que resulta em produtos, econômicos ou simbólicos, que podem ser obtidos a partir do capital social gerado, e que, por sua vez, é o insumo para realimentar o sistema, garantindo uma estabilidade dinâmica ou entropia negativa. Assim, os elementos de uma abordagem sistêmica (entrada, processo, saída e retroalimentação) podem ser identificados.

O utilitarismo também pode ser observado no texto de Bourdieu, corroborando a análise de Portes (1998), porém em menor predominância do que o sistemismo quando ele discute a natureza das redes de relações, afirmando que elas são o produto de estratégias de investimento social necessárias para produzir e reproduzir os laços duráveis e úteis para a obtenção de ganhos materiais ou simbólicos. Portes (1998) afirma que 
Bourdieu coloca foco nos benefícios acumulados pelos indivíduos por meio da participação em grupos e na construção deliberada da sociabilidade com o propósito de criar tais benefícios. Contudo, Bourdieu utiliza essa discussão para revelar a noção de uma sociedade estruturada por atores que tomam decisões em busca de benefícios próprios ou grupos de agentes pertencentes a estruturas que fornecem recursos distintivamente para eles por meio das dinâmicas sociais. Ou seja, essa discussão é direcionada para revelar uma sociedade estruturada por grupos com mais ou menos recursos, e marcada por conflitos nas suas dinâmicas sociais, caracterizando uma concepção do paradigma crítico, de acordo com Chanlat e Séguin (1987).

Quando discute sobre a concentração de capital social em um ator ou em um pequeno grupo, Bourdieu (1980) destaca que cada grupo tem suas formas mais ou menos institucionalizadas de delegação, que lhe permitem concentrar a totalidade do capital social nas mãos de um único ator ou um pequeno grupo de atores com poder simbólico para representar o grupo, falar, agir e exercer autoridade em seu nome e, assim, exercer poder com a contribuição pessoal dos atores. Ele ainda afirma que existe uma concorrência interna nos grupos para conseguir uma posição de nobre, sendo capaz de se apropriar da concentração de capital social.

Em 1986, é publicado o Handbook of Theory and Research for the Sociology of Education, editado por John G. Richardson, que traz um capítulo escrito por Bourdieu sobre a transmissão e a reprodução da educação. Nesse capítulo, Bourdieu (1986) explora com mais detalhes sua concepção do capital social como algo que é feito de obrigações sociais e é convertível em capital econômico em certas condições, e pode ser institucionalizado na forma de título de nobreza. Nessa ocasião, o autor retoma seu conceito de 1980, adicionando a ideia de que o capital social oferece a cada um dos membros de um grupo o apoio do capital de propriedade coletiva, como uma credencial que lhes dá crédito em vários sentidos (BOURDIEU, 1986). Assim, ele se apoia mais uma vez na abordagem sistêmica ao reconhecer a apropriação do capital social pelos indivíduos, ao mesmo tempo em que o reconhece como uma propriedade coletiva. Os sistemas no nível dos grupos sociais alimentam os sistemas no nível dos indivíduos e vice-versa, na produção de capital social.

Bourdieu (1986) acrescenta uma discussão sobre a propriedade de conversibilidade do capital. O capital social precisa ser estabelecido e mantido por um longo tempo para ser capaz de agir no momento apropriado para a obtenção de outras formas de capital. A transformação do capital econômico em capital social pressupõe um esforço específico, um gasto aparentemente gratuito de tempo, atenção, cuidado ou preocupação, que, do ponto de vista estritamente econômico, é visto como desperdício puro, mas é um investimento sólido em termos da lógica da troca social, pois os seus lucros irão aparecer a longo prazo, na forma monetária ou em outras formas. Nessa discussão, o autor se apoia novamente nos princípios do sistemismo ao considerar o processo de conversão de um tipo de recurso em outro, focando no elemento processual dos sistemas, que utiliza determinados insumos para realizar produtos a partir de processos específicos. Ainda sobre a propriedade de conversibilidade do capital, o autor afirma que a conversibilidade de capital econômico em capital social serve à reprodução de uma classe dominante na estrutura social, pois a conversibilidade dos diferentes tipos de capital é a base das estratégias destinadas a garantir a reprodução do capital. Está, nesse ponto, o argumento distintivo da noção sobre capital social de Bourdieu, caracterizado por elementos do paradigma crítico, de acordo com Chanlat e Séguin (1987), como a imersão sociológica e desmistificadora, não obstante a predominância do sistemismo, que é um elemento do paradigma funcionalista.

Por sua vez, James S. Coleman era norte-americano, foi professor de Sociologia na Universidade de Chicago, um sociólogo de renome mundial e faleceu em 1995. A carreira acadêmica de Coleman foi dedicada à criação e utilização de novas metodologias e teoria das ciências sociais para esclarecer questões de política pública (UNIVERSITY OF CHICAGO, 1995).

Em 1987, Coleman (1987) publicou um capítulo de um livro sobre imperialismo econômico intitulado Norms as Social Capital, onde ele sinaliza que as normas sociais constituem o capital social, de modo que elas resultam em níveis consideráveis de satisfação geral dos membros de uma comunidade. Ao explicar como as normas sociais constituem o capital social, Coleman (1987) busca sinalizar para elementos que caracterizam tanto uma análise sistêmica, ao considerar uma análise que passa de um nível micro para o 
nível macro da sociedade, quanto elementos que caracterizam o utilitarismo, uma vez que se reporta à satisfação dos indivíduos como elemento central das suas afirmações.

Um ano depois, Coleman (1988) publicou o artigo Social Capital in the Creation of Human Capital, onde ele introduz e exemplifica o conceito de capital social, descrevendo suas formas e examinando as condições da estrutura social sob a qual ele surge. Com base nesse artigo, o capital social é conceituado como uma ferramenta para ajudar na importação do princípio econômico da ação racional, considerando a organização social para usar na análise do sistema social adequado, incluindo o sistema econômico, sem se limitar a ele. Coleman (1988) examina a utilidade desse conceito no contexto particular da educação. Nesse artigo, o autor estabelece que "o capital social é definido por sua função. Ele não é uma entidade individual, mas uma variedade de diferentes entidades com dois elementos comuns: todas elas consistem em algum aspecto das estruturas sociais e elas facilitam certas ações dos atores - sejam pessoas ou atores corporativos - dentro da estrutura" (COLEMAN, 1988, p. 98, tradução nossa). No próprio conceito de capital social de Coleman (1988), é possível encontrar características que associam esse tema tanto às correntes utilitarista e funcionalista nas ciências sociais, quanto à concepção teleológica da organização no paradigma funcionalista. A discussão sobre o conceito de capital social de Coleman (1988) também apresenta características que o aproxima das abordagens sistêmicas, uma vez que considera diferentes níveis de análise da sociedade de maneira interdependente.

Uma forma de capital social depende da confiabilidade do ambiente social, no sentido de que as obrigações são realizadas e da extensão real das obrigações mantidas (COLEMAN, 1988). Sem um alto grau de confiabilidade entre os membros de um grupo, ou por uma falta de capital social, as instituições baseadas na confiança, como associações de crédito rotativo, não podem existir. Ao tratar das obrigações, expectativas e confiabilidade nas estruturas sociais como forma de capital social, Coleman (1988) faz considerações que fortalecem o caráter sistêmico e utilitarista de sua abordagem. Segundo ele, o capital social constitui a concentração de obrigações úteis para aumentar o nível de ação, criadas pelo uso efetivo de certos recursos. As relações são valiosas pelo "crédito" que fornecem na forma de obrigações que alguém cumpre para o desempenho do outro ou pela confiabilidade da outra parte.

Outra poderosa forma de capital social é constituída por normas quando elas existem e são efetivas (COLEMAN, 1988). Dentro de uma coletividade, a norma prescritiva de alguém renunciar os interesses próprios e agir nos interesses da coletividade constitui uma forma particularmente importante de capital social. Normas desse tipo direcionam as pessoas a trabalhar pelo bem público. Em alguns casos, as normas são internalizadas; em outros, elas são amplamente suportadas por recompensas externas para ações altruístas e reprovações de ações egoístas. Coleman (1988) traz características da dialética, especialmente a revelação de contradições, para discorrer sobre as normas sociais e as sanções efetivas como forma de capital social, ao afirmar que essa forma de capital social facilita certas ações e restringe outras. As normas prescritivas que recompensam certas ações direcionam as ações para longe de outras atividades. As normas desse tipo são importantes na superação dos problemas relacionados ao bem público na coletividade, independentemente de serem suportadas por sanções internas ou externas.

A propriedade de fechamento das relações sociais é responsável pela eficácia das normas (COLEMAN, 1988). A falta de fechamento na estrutura social é a razão pela qual as normas não se concretizam para limitar efeitos externos negativos ou encorajar efeitos positivos. Por meio do fechamento nas relações sociais, as forças dos atores são combinadas para restringir ações e fornecer sanções ou recompensas coletivas que podem monitorar e guiar o comportamento dos atores. Nessa discussão, é possível perceber princípios da corrente sistêmica quando ele propõe a propriedade de fechamento das relações sociais como facilitador de capital social. Coleman (1988) afirma que essa propriedade é resultado da combinação de forças para restringir ações e fornecer recompensas e sanções coletivas, de forma que retoma a característica sinérgica dos sistemas abertos, colocando o resultado das ações coordenadas das partes de maneira superior à soma dos resultados das ações individuais. 
Coleman (1988) também discute que um importante capital social é constituído quando uma organização criada para um propósito se torna disponível para outros propósitos entre os membros individuais, que tem os recursos organizacionais necessários à sua disposição. Uma vez criadas para atender a um conjunto de propósitos, uma organização também pode ajudar a atender outros propósitos, constituindo, assim, capital social disponível para ser usado. Essas organizações são outro ponto nas estruturas sociais que facilitam o surgimento de capital social na discussão de Coleman (1988). Nesse ponto, é possível perceber que o autor reforça as características utilitaristas e funcionalistas na sua discussão.

O efeito do capital social na criação de capital humano inter-geracional é particularmente importante, considerando o capital social na família e na comunidade (COLEMAN, 1988). Coleman (1988) apresenta o empirismo fortemente nessa discussão ao tratar do papel do capital social na criação de capital humano, considerando os ambientes familiares e comunitários para o desenvolvimento dos jovens. Um fato interessante é que, para ilustrar sua discussão, esse autor faz referências à vida pessoal de John Stuart Mill e Jeremy Bentham, dois pesquisadores consagrados da corrente utilitarista, na qual Coleman (1988) busca fundamentos diversas vezes. Esse autor utiliza uma análise de dados estatísticos com foco na generalização dos resultados por meio da indução.

A maior parte das ideias apresentadas por Coleman em seu artigo de 1988 foi utilizada na composição do capítulo específico sobre capital social no livro Fundamentos da Teoria Social (COLEMAN, 1990). Nesse livro, o autor acrescenta algumas ideias. As relações de autoridade são vistas como uma forma de capital social disponível para um ator na forma de direitos de controle, que pode ser concentrado em determinadas atividades. Isso coloca um ator em um poder extenso. $\mathrm{O}$ desejo de fazer existir o capital social necessário para resolver problemas comuns leva as pessoas em certas circunstâncias a delegar autoridade a um líder carismático. Quando se refere às relações de hierarquia como forma de capital social, Coleman (1990) recorre a uma concepção teleológica da organização. A estabilidade também é tratada como um fator do qual toda forma de capital social depende, considerando que as rupturas da organização social ou das relações sociais podem ser altamente destrutivas ao capital social. A concepção integradora e não conflitual do paradigma funcionalista das organizações aparece quando Coleman (1990) trata da estabilidade como fator para a manutenção do capital social.

\section{Capital social nas ciências políticas}

Nesta seção, são consideradas as contribuições de Robert Putnam e Francis Fukuyama sobre a teoria do capital social. Robert D. Putnam é professor de Políticas Públicas em Harvard e tem sido consultado sobre capital social por vários líderes estatais ao redor do mundo. Robert D. Putnam estudou o capital social e as condições necessárias para criar instituições fortes, responsáveis e eficazes na experiência regional italiana em uma pesquisa que durou aproximadamente 20 anos. Ele observou a influência de fatores ambientais como o contexto econômico e a tradição política no desempenho de governos regionais com estrutura organizacional similar. Esse estudo foi publicado originalmente em 1993, no seu livro Making Democracy Work: Civic Traditions in Modern Italy (PUTNAM, 2002).

Inicialmente, Putnam (2002) faz referências à filosofia de David Hume, especificamente à parábola dos fazendeiros para desenvolver suas ideias sobre a ação coletiva. Esse filósofo é consagrado como um empirista, defensor do utilitarismo e do pensamento teleológico. Portanto, é dessa base que nascem as ideias sobre o capital social de Putnam (2002). Para ele, os dilemas da ação coletiva, que se referem à escolha do comportamento oportunista nas relações sociais, refutam as tentativas de cooperar em benefício mútuo em toda a sociedade. A cooperação voluntária depende do capital social. O capital social é composto pelo compartilhamento de regras, confiança e redes sociais em um processo dinâmico. As normas compartilhadas originam regras de reciprocidade generalizada e as redes sociais formam sistemas de participação cívica. As regras de reciprocidade generalizada e os sistemas de participação cívica fazem surgir relações de confiança entre os membros de um grupo que reduzem os incentivos a transgredir, diminuem as incertezas e estimulam 
a cooperação. A incapacidade de cooperar é devida ao oportunismo. Devido à falta de compromisso mútuo e confiável, ambas as partes, que poderiam ganhar se cooperassem, preferem se comportar de maneira oportunista. Nessa situação, a coerção de um terceiro é uma solução inadequada. O uso de poder nas sociedades faz com que elas se tornem menos eficientes, mais sacrificantes e menos satisfatórias.

Nesse livro, Putnam (2002, p. 177) define capital social como as "características da organização social, como confiança, normas e sistemas, que contribuam para aumentar a eficiência da sociedade, facilitando as ações coordenadas". Ao demonstrar a importância do capital social pela investigação da experiência italiana, Putnam (2002) recorre à perspectiva histórica nas suas análises, considerando que ricas redes de reciprocidade organizadas, bem como a solidariedade cívica, estão no centro da herança cívica trazida pela história das comunidades civilizadas. Os registros históricos sugerem que essas comunidades se tornaram ricas porque elas eram civilizadas, sendo o capital social associado às normas e redes de engajamento cívico uma condição para o desenvolvimento econômico e para o governo efetivo. Essas redes também estão associadas aos sucessos passados de colaboração que servem como um modelo cultural para as próximas colaborações, sendo um repertório histórico de formas de cooperação que estão disponíveis aos cidadãos para solucionar novos problemas de ação coletiva. O estoque de capital social, tal como confiança, normas e redes, tende a ser de auto-reforço e cumulativo. As colaborações bem sucedidas em um esforço constroem conexões e confiança, que são ativos sociais que facilitam as colaborações futuras em outras tarefas não relacionadas.

Putnam (2000) analisa a sociedade norte-americana, mostrando como houve um declínio no sentimento de pertencimento comunitário entre os cidadãos. Esse estudo está no livro Bowling Alone, publicado em 2000. Nesse momento, Putnam (2000) afirma que a principal ideia da teoria do capital social é que as redes sociais têm valor, uma vez que os contatos sociais aumentam a produtividade dos indivíduos e grupos. Putnam (2000) aproxima sua definição de capital social para os princípios do funcionalismo, enfatizando o caráter produtivo do capital social fazendo comparações com o capital físico e humano, como é mostrado no seguinte trecho: "Por analogia com as noções de capital físico e capital humano - ferramentas e treinamento que aumentam a produtividade individual - a ideia central da teoria do capital social é que as redes sociais têm valor. Bem como uma chave de fenda (capital físico) ou uma formação superior (capital humano) pode aumentar a produtividade (individual e coletiva), os contatos sociais também afetam a produtividade dos indivíduos e dos grupos" (PUTNAM, 2000, p. 18-19, tradução nossa).

Putnam (2000) considera que à medida que os primeiros baby boomers se aproximaram da faculdade nos anos 1960, surgiram os sinais de crescente vitalidade cívica. Ele reconhece que dezenas de estudos confirmaram que a educação era o melhor preditor de engajamento na vida cívica, e que as universidades estavam em expansão na história americana. A maior tolerância e o maior envolvimento social seriam alcançados por meio da educação. Os universitários brancos na região norte começaram a se mobilizar, sendo inspirados pelos jovens afro-americanos na região sul que iniciaram a luta pelos direitos civis. Ao fazer essa explanação sobre a sociedade norte-americana, Putnam (2000) recorre novamente à perspectiva histórica de um lado, mas, por outro lado, também ressalta a importância do conjunto de estudos anteriores, com a pretensão de generalização própria do positivismo. Além do destaque dado à perspectiva histórica na abordagem de Putnam (2000; 2002), também é importante destacar uma forte base empírica que está presente nas suas análises. O posicionamento desse autor é decorrente das suas avaliações empíricas, sejam na sua investigação nas comunidades italianas ou na sua investigação acerca das mudanças da sociedade norte-americana.

Ao tratar das mudanças na sociedade norte-americana, Putnam (2000) considera que o capital social também tem um aspecto individual, além do aspecto coletivo. Em sua visão, o capital social pode ser, simultaneamente, um bem privado e um bem público. Uma parte do benefício gerado no capital social vai para o coletivo, enquanto parte do benefício recai ao interesse imediato da pessoa que faz o investimento. Nesse ponto, ele aceita a contradição de que o capital social é um recurso que, ao mesmo tempo em que é de uma coletividade, não sendo propriedade privada de um ator, ele também pode ser usado por cada indivíduo 
para satisfazer seus próprios interesses. Assim, é possível perceber que ele recorre à dialética para revelar um fenômeno permeado pela contradição entre propriedade privada e coletiva.

Putnam (2000) ressalta que o capital social pode ser utilizado para facilitar o alcance de fins antissociais como um ataque terrorista ou as manifestações urbanas de gangues. As redes e as normas de reciprocidade associadas são geralmente boas para aqueles dentro da rede, mas os efeitos externos do capital social não são sempre positivos. Uma rede de amigos colocados juntos por meio de uma norma de reciprocidade permite que eles façam algo socialmente inaceitável que não fariam sozinhos. O capital social pode ser explorado para alcançar fins que são antissociais de um amplo ponto de vista. Em resumo, o capital social pode ser direcionado para propósitos antissociais e maléficos. Nessa discussão, o princípio utilitarista se faz presente, pois a utilização de capital social, mesmo para o alcance de fins antissociais, continua sendo vista como um meio de satisfazer os propósitos dos atores.

As formas mais importantes de diferenciação do capital social são a forma de ponte e de união (PUTNAM, 2000). O capital social de união é uma forma com olhar interno e tende a reforçar identidades exclusivas e grupos homogêneos, seja por necessidade ou por escolha. Essa forma é boa para envolver uma reciprocidade particular, mobilizar solidariedade e apoiar identidades estreitas. Uma vez que o capital social de união cria uma forte lealdade interna, ela também pode criar um forte antagonismo para fora do grupo, sendo possível esperar efeitos externos negativos. Por sua vez, o capital social de ponte é uma forma com olhar externo e abrange pessoas em clivagens sociais diversas, sendo melhor para alcançar ativos externos e para difundir informação. Além disso, o capital social de ponte pode gerar identidades e reciprocidades mais amplas. $\mathrm{O}$ capital social de ponte e de união são dimensões que apresentam presença relativa e possível de comparação. Quando Putnam (2000) trata da forma de capital social de união, a contradição inerente ao processo dialético pode ser percebida. Ele destaca que essa forma de capital social é, ao mesmo tempo, promotora de similaridades e de antagonismos, pois ela reforça a interação entre pessoas com alguma semelhança, ao mesmo tempo em que intensifica a aversão às diferenças sociais.

Por sua vez, Francis Fukuyama, cientista político que já foi membro da Equipe de Planejamento Político do Departamento de Estado dos Estados Unidos e atualmente é pesquisador sênior no Centro de Democracia, Desenvolvimento e Estado de Direito na Universidade de Stanford (STANFORD UNIVERSITY, 2012), em 1995, publicou o livro Confiança, no qual estabeleceu suas discussões iniciais sobre a importância do capital social no processo de desenvolvimento de uma nação. O terceiro capítulo desse livro, intitulado escala $e$ confiança, traz as bases da concepção sobre o capital social na sua visão. Fukuyama (1996, p. 41) conceitua o capital social como "uma capacidade que decorre da prevalência de confiança em uma sociedade ou em certas partes dessa sociedade", podendo estar incorporada nos diversos grupos sociais do nível familiar ao nível nacional. $\mathrm{O}$ autor também considera que são os mecanismos culturais que geralmente criam e transmitem o capital social. É possível associar a conceituação e as considerações iniciais de Fukuyama aos princípios do sistemismo, pois ressalta que a sociedade é um sistema constituído por subsistemas que se referem a grupos sociais em diferentes níveis, bem como trata o capital social como algo que é criado, ou, nos termos do sistemismo, é o produto ou resultado de um processo cultural que se realiza dentro de um sistema social.

De acordo com Fukuyama (1996), o capital social é baseado no predomínio de virtudes sociais e sua aquisição requer o hábito às normas morais de uma comunidade e a aquisição de virtudes como lealdade, honestidade e confiabilidade, sendo essas as capacidades de formar novas associações e cooperar com os termos que estabelecem o tipo de capital social mais útil. Assim, o utilitarismo se faz presente pelo reconhecimento de que o capital social é capaz de realizar atividades que beneficiam os indivíduos por meio de associações sociais e das ações de cooperação.

Fukuyama (1996) afirma que a natureza da economia industrial em uma sociedade sofre consequências do capital social, que pode ser mais forte nos laços de parentesco ou em associações voluntárias na sociedade como um todo. $\mathrm{O}$ autor estabelece que a capacidade de criar grandes organizações privadas lucrativas se faz presente nas sociedades de alta confiança com abundante capital social, marcadas por associações 
voluntárias na sociedade como um todo. Essas afirmações reforçam o aspecto sistêmico inerente às ideias do autor, pois trata as associações voluntárias como um elemento importante para manutenção do sistema econômico, que tende à estagnação e ao processo entrópico na ausência de tais associações.

Além disso, Fukuyama (1996) também afirma que, à medida que a tecnologia e os mercados mudam, novas formas organizacionais poderão ser adotadas pelas sociedades com alto capital social mais rapidamente. Relacionado a isso, o autor destaca que o capital social precisa ser contado como um recurso das nações, pois as diferentes posses trazem implicações para a divisão global do trabalho. Assim, o autor também recorre aos princípios funcionalistas nas suas ideias, uma vez que atribui a função de facilitar a superação de dificuldades ao capital social, bem como de garantir vantagens econômicas às nações. $\mathrm{O}$ autor encerra seu texto afirmando que o capital social torna uma organização mais eficiente.

Em 1995, é publicado o artigo Social capital and the global economy de Fukuyama (1995), que é uma adaptação do livro Confiança. Nesse artigo, Fukuyama (1995) afirma que as diferenças entre as organizações econômicas na estrutura industrial estão relacionadas ao capital social, tomado como o componente do capital humano que permite aos membros de uma determinada sociedade confiar uns nos outros e cooperar na formação de novos grupos e associações de negócios. Em sua visão, as organizações econômicas podem ser negócios familiares ou formas flexíveis de organizações baseadas na sociabilidade espontânea que surge da confiança mútua entre pessoas estranhas que, por sua vez, são enfraquecidas em culturas que enfatizam fortemente os laços familiares. Nessa discussão, o autor também recorre aos princípios funcionalistas ao destacar que o capital social está relacionado à eficiência das organizações econômicas. O pensamento dicotômico típico do funcionalismo também aparece nas considerações sobre organizações familiares ou organizações flexíveis, excluindo a possibilidade de existirem organizações familiares e flexíveis.

O mesmo autor ressalta que é possível que uma sociedade seja deficiente em capital social em todos os sentidos por não ter nem fortes laços familiares nem fortes associações espontâneas sem parentescos, fazendo surgir organizações criminais como a principal forma de organização social. Ele ainda destaca que o capital social precisa ser periodicamente renovado para não se extinguir. Nessa discussão, é possível observar, mais uma vez, os princípios sistêmicos ao se pensar na extinção do capital social como resultado de um processo entrópico, no qual o sistema deixa de ser alimentado com seus recursos essenciais que, nesse caso, são os laços de confiança entre familiares ou entre desconhecidos, fazendo as organizações criminosas aparecerem como um sistema que substitui o anterior.

Fukuyama (1995) chama atenção para as formas nas quais diferentes sociedades surgem com posses relativas de capital social. Enquanto muitas sociedades de base familiar com um baixo grau de confiança entre desconhecidos passaram por um período de centralização estatal absoluta que extinguiu tal capital social, as sociedades com alto grau de confiança social nunca passaram por longos períodos de poder estatal centralizado. Quando se trata de aspectos econômicos, o autor destaca que tanto a necessidade de uma política industrial quanto a habilidade para implementar tal política, efetivamente, dependem de fatores culturais como o capital social. Essa discussão revela uma abordagem em perspectiva histórica, que é um elemento do paradigma crítico, de acordo com Chanlat e Séguin (1987), pois o autor constrói uma lógica para a formação econômica e social de países como Estados Unidos, Japão, Alemanha, China, Itália e França a partir do resgate de aspectos históricos e culturais de tais nações. Contudo, apesar da perspectiva histórica se fazer presente ao longo de todo o texto, não é possível afirmar que Fukuyama desenvolve uma concepção crítica de capital social devido à predominância de outros elementos que reforçam um caráter funcionalista.

No ano 2000, é publicado o livro A grande ruptura, no qual Fukuyama continua fazendo a associação entre o desenvolvimento econômico e o capital social de uma sociedade. Nesse livro, ele afirma que o capital social é um pré-requisito para as formas de empreendimento em grupo na sociedade moderna e tem valor para uma economia nacional devido à sua capacidade de produzir riqueza. Assim, o autor reforça as bases utilitaristas e sistêmicas nas suas ideias, uma vez que considera que o capital social é capaz de produzir riqueza para beneficiar os indivíduos e também é um elemento indispensável como recurso dos sistemas sociais que produzem essas riquezas. 
Nesse livro, Fukuyama (2000, p. 28) define o capital social como "um conjunto de valores ou normas informais, comuns aos membros de um grupo, que permitem a cooperação entre eles". Contudo, o autor ressalta que alguns valores e normas comuns podem não produzir capital social quando intensificam a falta de confiança, como em contextos com a predominância das organizações criminosas. Tais normas impossibilitam a cooperação social, enquanto as normas que produzem capital social incluem honestidade, cumprimento de obrigações e reciprocidade. Essa discussão mostra que o autor revela contradições inerentes ao capital social, aprofundando a compreensão desse fenômeno por meio da dialética. Apesar de o autor supor que a existência de capital social é algo bom para a sociedade, ele reconhece que também pode ser prejudicial quando colocado à disposição das organizações criminosas, de ódio racial ou de intolerância.

Na visão de Fukuyama (2000), a ausência de capital social pode ser compensada por mecanismos de coordenação formal, como contratos, hierarquias, constituições e leis para o sucesso dos grupos sociais. O autor destaca que o capital social facilita o sucesso de um grupo social na forma de inovação e adaptação, bem como destaca que pode trazer benefícios para a sociedade civil, por permitir que diferentes grupos sociais se unam para defender seus interesses. Para o autor, uma democracia bem sucedida precisa da sociedade civil que, por sua vez, precisa de capital social para existir. Assim, o autor ressalta o caráter utilitarista do capital social como uma ferramenta útil para alcançar os interesses e o sucesso dos grupos sociais.

Fukuyama (2000) também discute a mensuração do capital social e apresenta dados relacionados aos países desenvolvidos para sustentar seus argumentos por meio de uma análise comparativa. $\mathrm{O}$ autor justifica que a análise comparativa é uma ferramenta adequada para entender a causa de um determinado efeito nas ciências sociais, fazendo uma analogia ao método experimental das ciências naturais, e fazendo referência ao estudo de Emile Durkheim sobre o suicídio como marco desse tipo de análise. Portanto, o autor parece se posicionar claramente em um alinhamento epistemológico que aproxima os princípios empiristas e funcionalistas dentro de um escopo positivista.

\section{Capital social na administração}

Sumantra Ghoshal atuou como professor de liderança estratégica na Faculdade de Negócios de Londres desde 1994, até seu falecimento em 2004. Ele desenvolveu um grande número de seguidores inspirados por suas pesquisas, consultorias, colunas de jornal e uma série de televisão (CAULKIN, 2004). Em 1997, é publicado o livro The differentiated network de Ghoshal em coautoria com Nitin Nohria, que é professor na Faculdade de Negócios de Harvard e era professor visitante na Faculdade de Negócios de Londres naquele momento. Em um capítulo desse livro sobre redes interpessoais como mecanismo de integração, os autores exploram alguns fatores que afetam o capital social desenvolvido por gestores departamentais em corporações multinacionais, definindo o capital social como a rede de contatos dos indivíduos. Uma alta densidade de relações dentro dos grupos sociais leva à circulação de muitas informações redundantes, perdendo informações novas de outros grupos e do ambiente externo. Essas lacunas entre grupos sociais na estrutura de fluxo de informação formam furos estruturais, que são os espaços vazios na estrutura social e têm o valor potencial de servir como fontes de informações não redundantes e complementares (BURT, 2005). Tomando a variedade de contatos não redundantes como o indicador de capital social, os autores afirmam que os indivíduos com mais capital social são mais prováveis de serem bem sucedidos em seus trabalhos e evoluírem nas suas carreiras, assim como as organizações com indivíduos com mais capital social são mais prováveis de terem vantagens competitivas. Assim, as ideias expostas pelos autores ressaltam a capacidade do capital social de fornecer benefícios para os indivíduos e para as organizações, fazendo uso de princípios utilitaristas. Além disso, também é possível observar a presença do sistemismo, uma vez que a interface entre os subsistemas individuais e os sistemas organizacionais é explorada.

Por meio de um estudo empírico com gestores de três grandes corporações multinacionais, os autores investigaram o papel de fatores, como ter contatos expatriados, treinamento inicial e relacionamentos de 
mentoria como potenciais determinantes do capital social dos indivíduos na corporação multinacional, tomado como uma variável que depende de certos fatores. Por um lado, essa investigação ressalta a base empirista nas contribuições dos autores; e por outro lado, a operacionalização da investigação revela princípios do sistemismo por considerar o capital social como o resultado que depende do processo de outros fatores em um sistema aberto.

Em uma edição da Academy of Management Review em 1998, foi publicado um artigo sobre capital social de Ghoshal em coautoria com Janine Nahapiet, professora da Universidade de Oxford. Segundo os autores, o pressuposto central da teoria do capital social é que as redes de relacionamentos constituem um recurso valioso para a condução de assuntos sociais. Eles definem o capital social como "... a soma de recursos atuais ou potenciais imersos nas, disponíveis pelas, e derivados das redes de relacionamentos pertencentes a um indivíduo ou unidade social" (NAHAPIET e GHOSHAL, 1998, p. 243, tradução nossa). É possível associar tal definição aos princípios do sistemismo, especialmente ao aspecto sinérgico, uma vez que considera o capital social como algo que é constituído pela soma de outros recursos, como também considera a presença de sistemas e subsistemas ao tratar do pertencimento das redes de relacionamentos aos indivíduos ou unidades sociais. A partir dos princípios do sistemismo, também é possível entender o capital social como o resultado de um processo originado nas redes sociais, e que é disponibilizado como insumo para outro sistema.

Nahapiet e Ghoshal (1998) definiram o capital social a partir de três dimensões distintas e inter-relacionadas, considerando a integração de suas diferentes facetas: dimensão estrutural, dimensão relacional e dimensão cognitiva. A dimensão estrutural se refere ao padrão geral de conexões sociais entre os atores. A dimensão relacional se refere a ativos criados e impulsionados por imersões em relacionamentos específicos. A dimensão cognitiva se refere a recursos que fornecem representações, interpretações e sistemas de significações compartilhados entre os atores. A abordagem discutida pelos autores, ao separar o capital social em três dimensões, traz consigo o princípio central do racionalismo cartesiano, sendo esta uma característica central do texto como um todo, uma vez que é a principal contribuição para o tema e permeia todo o texto.

As consequências do capital social para a ação são discutidas por Nahapiet e Ghoshal (1998), afirmando que aumenta a eficiência da ação e diminui a probabilidade de oportunismo, reduzindo a necessidade de custear processos de monitoramento. Assim, o capital social ajuda na eficiência adaptativa e no aprendizado subjacente. É possível associar essa discussão aos princípios funcionalistas, pois estes pressupõem que o capital social cumpre funções facilitadoras da eficiência organizacional, além de pressupor uma função adaptativa análoga à ideia evolutiva dos sistemas biológicos.

Os autores também reconhecem que o capital social, na forma de fortes normas e identificação mútua, não é um recurso universalmente benéfico, podendo limitar a entrada de informação em um grupo e o uso de meios alternativos para realizar objetivos que, por sua vez, produzem uma cegueira coletiva que eventualmente leva a consequências desastrosas. Tal consideração realizada pelos autores revela certa contradição inerente à natureza do capital social, sendo este bom e mau ao mesmo tempo, podendo estar associado à uma concepção dialética.

Nahapiet e Ghoshal (1998) argumentaram que a teoria do capital social fornece uma base poderosa para compreender a criação de capital intelectual e a natureza das vantagens organizacionais, uma vez que as empresas são mais dotadas de capital social do que o mercado, como um arranjo institucional. Para construir esse argumento, os autores se baseiam em uma ampla literatura, ressaltando os resultados de diversas pesquisas empíricas anteriores que corroboram o argumento, apoiando-se, portanto, em princípios positivistas.

Com base em seu artigo teórico com Janine Nahapiet, Ghoshal desenvolve uma pesquisa empírica para verificar como o capital social contribui para a competência de uma empresa criar valor na forma de inovação, desta vez em coautoria com Wenpin Tsai, professor da Universidade do Estado da Pensilvânia (TSAI e GHOSHAL, 1998). De acordo com Tsai e Ghoshal (1998), o capital social é um recurso produtivo 
facilitador de ações que variam de realizações de ocupações individuais a operações de negócios empresariais. Por um lado, essa nova concepção de capital social complementa a anterior ao adicionar um aspecto utilitarista, ao ser considerado como um recurso utilizado para facilitar as dinâmicas sociais. Por outro lado, essa nova concepção mantém aspectos sistêmicos da concepção anterior, já que reconhece a variação entre os níveis individual e organizacional.

Uma característica central do texto de Tsai e Ghoshal (1998) é a predominância do empirismo. Os autores construíram hipóteses baseadas no modelo desenvolvido por Nahapiet e Ghoshal (1998) e as submeteram ao teste empírico com a aplicação de questionários em unidades de negócios de uma grande empresa multinacional de produtos eletrônicos. Os resultados do teste empírico fortalecem o modelo utilizado e discutem algumas discrepâncias, sugerindo futuras pesquisas, caracterizando uma forma de produção de conhecimento da corrente positivista. Nesse sentido, a corrente positivista está amplamente presente ao longo do texto, pois os autores recorrem a uma série de estudos anteriores para justificar e generalizar seus argumentos.

Tsai e Ghoshal (1998) destacam que o capital social engloba muitos aspectos de um contexto social, tais como os laços sociais, relações de confiança e sistemas de valores que facilitam as ações dos indivíduos inseridos no contexto. Mais uma vez, os autores se apoiam no princípio utilitarista de buscar meios que facilitem alguma realização benéfica para os indivíduos. Além disso, os autores associam esses aspectos às dimensões estrutural, relacional e cognitiva do capital social discutidas anteriormente por Nahapiet e Ghoshal (1998), retomando o caráter racionalista cartesiano presente na concepção do capital social em diferentes partes separadas que se inter-relacionam, por sua vez, tentando diminuir a complexidade do fenômeno para ser melhor compreendido.

As dimensões estrutural, relacional e cognitiva do capital social são retomadas por Tsai e Ghoshal (1998) destacando os seguintes aspectos: a dimensão estrutural ressalta a posição dos contatos de um ator em uma estrutura social que fornece certas vantagens como conseguir trabalho, obter informações e acessar recursos específicos. A dimensão relacional se refere aos ativos que sustentam os relacionamentos, tais como confiança e confiabilidade, possibilitando a um ator confiável conseguir o apoio de outros atores para alcançar seus objetivos. A dimensão cognitiva se refere a atributos, como uma visão compartilhada ou um conjunto de valores comuns que ajuda os indivíduos e grupos a realizar ações capazes de beneficiar toda a organização. Assim, é possível perceber uma base utilitarista nas considerações dos autores para as três dimensões do capital social, uma vez que destacam as vantagens da estrutura social, o alcance de objetivos por meio da confiança e os significados compartilhados que beneficiam a organização.

Ao discutir as inter-relações entre as três dimensões do capital social, Tsai e Ghoshal (1998) avançam na teorização proposta por Nahapiet e Ghoshal (1998). De acordo com os autores, a dimensão estrutural e a dimensão relacional se relacionam devido à possibilidade dos laços de interações sociais estimularem a confiança e a confiabilidade percebidas. A dimensão relacional e a dimensão cognitiva se relacionam devido à possibilidade do desenvolvimento das relações de confiança ser estimulado por valores comuns e uma visão compartilhada. A dimensão estrutural e a dimensão cognitiva se relacionam devido ao papel assumido pelas interações sociais tanto no estabelecimento de um conjunto de objetivos e valores comuns, quanto no compartilhamento desses objetivos e valores entre os membros de uma organização. Os autores destacam que cada dimensão do capital social reforça a existência das outras dimensões. Toda essa discussão acerca das inter-relações entre as dimensões do capital social é permeada por princípios sistêmicos, uma vez que cada dimensão é um subsistema de elementos que interagem para fornecer um resultado para um sistema maior, que é o capital social. O aspecto sinérgico do sistemismo também fica evidente na afirmação de que cada dimensão reforça a existência das outras, sugerindo que o resultado alcançado por cada dimensão é potencializado quando as outras dimensões se fazem presentes.

O quadro 4 resume as análises apresentadas nesse estudo, apontando para a presença de elementos das diferentes correntes epistemológicas nas contribuições analisadas de cada autor sobre capital social, bem como indica o seu posicionamento em um paradigma funcionalista ou crítico. 
Quadro 4

Análise epistemológica do capital social

\begin{tabular}{|c|c|c|c|c|c|}
\hline & Bourdieu & Coleman & Putnam & Fukuyama & Ghoshal \\
\hline Empirismo & & $x$ & $x$ & & $x$ \\
\hline Racionalismo & & & & & $x$ \\
\hline Utilitarismo & $x$ & $x$ & $x$ & $x$ & $x$ \\
\hline Positivismo & & & $x$ & & $x$ \\
\hline Funcionalismo & & $x$ & $x$ & $x$ & \\
\hline Sistemismo & $x$ & $x$ & & $x$ & $x$ \\
\hline Dialética & & & $x$ & $x$ & \\
\hline $\begin{array}{l}\text { Paradigma } \\
\text { Funcionalista }\end{array}$ & & $x$ & $x$ & $x$ & $x$ \\
\hline Paradigma Crítico & $x$ & & & & \\
\hline
\end{tabular}

Fonte: Elaborado pelos autores.

\section{O capital social na área da administração no contexto brasileiro}

A produção científica brasileira sobre capital social no âmbito da administração teve início em torno do ano 2001, no qual o primeiro artigo sobre o tema foi publicado no Encontro da Associação Nacional de Pesquisa e Pós-Graduação em Administração (ANPAD). O período entre os anos de 2006 e 2007 representa o momento em que houve uma produção científica maior sobre capital social na área da administração, com vários artigos publicados no âmbito da ANPAD. Esta seção apresenta alguns estudos que refletem de maneira mais aprofundada as contribuições de Bourdieu, Coleman, Putnam, Fukuyama e Ghoshal, que são as referências predominantes nos artigos publicados sobre o tema desde 2001.

Ao discutir sobre o papel do capital social na superação da pobreza em áreas urbanas no Brasil, Helal e Neves (2007) reportam-se às contribuições de Bourdieu para o tema. Os autores destacam que a visão de Bourdieu sobre capital social é microssociológica, e partem dessa visão com a intenção de contribuir para as políticas públicas de redução e erradicação da pobreza. Helal e Neves (2007) destacam que Bourdieu é um dos principais representantes da visão de que o capital social pode ser internalizado pelo indivíduo. De acordo com esses autores, a visão microssociológica ressalta que o estoque de capital social de cada indivíduo é um recurso utilizado em benefício próprio, embora esse estoque seja dependente da rede de relações mobilizada pelo indivíduo e do volume de capital possuído pelos membros da rede. $\mathrm{O}$ estoque de capital social dos indivíduos é entendido pelos autores por meio da participação em grupos e associações. Os resultados da pesquisa realizada por Helal e Neves (2007) com dados sobre a Região Metropolitana de Belo Horizonte indicam que os indivíduos que participam de organizações sociais têm maiores chances de obter uma renda capaz de superar a situação de pobreza. 
As contribuições de Coleman dão suporte para Serafim e Andion (2010) explorarem a relação entre o capital social e o fenômeno da expansão de organizações religiosas no Brasil, mostrando como a ação empreendedora dos membros dessas organizações pode ser beneficiada por meio das redes sociais que facilitam o acesso e a mobilização de novos recursos. Esses autores entendem que a participação em organizações religiosas é uma fonte particular de capital social. Assim, Serafim e Andion (2010) consideram que a prática religiosa pode acionar os recursos geradores do capital social de acordo com o modelo de Coleman, como obrigações e expectativas, canais de informação, normas ou sanções, fortalecimento de laços sociais e organização social. A partir dos resultados de uma pesquisa de campo em organizações religiosas no Brasil, Serafim e Andion (2010) mostram que as estruturas religiosas dessas organizações formam um tipo particular de capital social, denominado por eles de capital espiritual, cujas características específicas, de acordo com os autores, não são suficientemente abordadas na teoria do capital social formulada por Coleman.

A noção de capital social elaborada por Putnam está presente no estudo de Fernandes (2010), que compara os conselhos municipais de saúde nas cidades de Salvador e Porto Alegre. Considerando a base teórica de Putnam, o estudo de Fernandes (2010) contribui para a investigação do capital social no contexto brasileiro, uma vez que realiza uma comparação entre os conselhos de saúde das cidades de Porto Alegre e Salvador, oferecendo uma explicação para os diferentes desempenhos nessas organizações. Porém, o autor ressalta que seu estudo não teve o intuito de explicar diferentes culturas políticas no Brasil, como é mostrado por Putnam no caso italiano. Ao analisar as atas das reuniões dos conselhos municipais de saúde, Fernandes (2010) destaca que existe maior efetividade, participação e autonomia institucional nessas organizações em Porto Alegre do que em Salvador. Segundo o autor, a explicação para essa diferença repousa nos processos de participação política, que foram reforçados pela elite política em Porto Alegre, enquanto sofreram resistência da elite política em Salvador nas últimas décadas.

A partir de uma discussão sobre a confiança nas relações sociais e a construção de capital social, incluindo as contribuições de Fukuyama e outros, Tonini e Macke (2007) identificaram a existência de confiança e do capital social na Associação dos Produtores de Vinhos Finos do Vale dos Vinhedos (APROVALE) na serra gaúcha. De acordo com as autoras, a visão de Fukuyama sobre a confiança destaca os aspectos culturais relacionados aos hábitos e tradições de uma população, que levam às suas consequências positivas ou negativas. De acordo com as autoras, a confiança existente entre os membros da APROVALE foi desenvolvida no passado para a associação obter o selo de indicação de procedência de seus vinhos e mantêlo atualmente para propiciar os benefícios econômicos relacionados ao seu uso, gerando um comprometimento entre os associados quanto à qualidade dos vinhos produzidos por eles. Assim, de acordo com Tonini e Macke (2007), o aspecto cultural da confiança destacado por Fukuyama parece não ter relação com a confiança existente entre os membros da APROVALE.

Tomando como base a abordagem de Ghoshal e seus colaboradores para o capital social, Régis, Dias e Bastos (2006) consideram que tal abordagem carece de maior clareza para explicar a formação de capital social associada ao comportamento organizacional. Assim, os autores desenvolvem essa abordagem, buscando reduzir a sua complexidade por meio de um estudo sobre a formação do capital social entre empresários participantes de incubadoras de empresas de base tecnológica no Recife. Nesse estudo, Régis, Dias e Bastos (2006) apresentam um procedimento multi-método para examinar o capital social, incorporando as dimensões estrutural, relacional e cognitiva apresentadas por Ghoshal e seus colaboradores. Os resultados mostram que o desenvolvimento e a manutenção de relacionamentos sociais são mais importantes para os empresários que participaram do estudo do que o isolamento social característico no desenvolvimento sigiloso de novas tecnologias. A abordagem de capital social apresentada no estudo de Régis, Dias e Bastos (2006) possibilitou, segundo os autores, a compreensão dos aspectos relevantes para o desenvolvimento de uma carreira empreendedora devido à redução da complexidade na compreensão do capital social e suas dimensões. 


\section{Considerações Finais}

Buscou-se, nesse artigo, apresentar uma classificação paradigmática das referências predominantes sobre a teoria do capital social na ciência da administração a partir da identificação dos princípios epistemológicos subjacentes, particularmente, sobre as contribuições de Pierre Bourdieu, James Coleman, Robert Putnam, Francis Fukuyama e Sumantra Ghoshal. Essa discussão foi capaz de revelar os princípios mais frequentes nas concepções e argumentos desses autores. De maneira geral, pode-se concluir que os princípios do utilitarismo e do sistemismo são predominantes nas concepções de capital social elaboradas pelos autores analisados.

Quando se trata da contribuição dos sociólogos ao discutirem sobre capital social, Pierre Bourdieu é conhecido historicamente como o primeiro autor a fornecer uma sistematização sobre o assunto (PORTES,1998), sendo citado costumeiramente na apresentação do tema, em vez de ser citado pelo possível alinhamento epistemológico dos autores que o citam. Em suma, a partir da análise realizada, é possível afirmar que Bourdieu recorre, majoritariamente, aos princípios da corrente sistêmica e considera princípios utilitários eventualmente. Apesar do alinhamento entre os princípios do utilitarismo e do sistemismo ao paradigma funcionalista, a noção sobre capital social de Bourdieu é caracterizada por elementos do paradigma crítico, como a imersão sociológica e desmistificadora, fortalecendo a base fundamentada por Loury (1977). Quando se trata da contribuição de Coleman sobre capital social, a sua obra é amplamente marcada por bases utilitaristas e funcionalistas, mas é no sistemismo que esse autor tem sua base mais forte para tratar do tema. As discussões apresentadas por ele são nutridas por diversos elementos da abordagem sistêmica. O empirismo também é um elemento forte nas suas discussões.

Quando se trata das contribuições dos cientistas políticos, os desdobramentos de Putnam sobre capital social possuem alguns elementos epistemológicos amplamente presentes. Ele fundamenta seus estudos em uma perspectiva histórica da sociedade, bem como na investigação empírica. Ele também segue uma racionalidade indutivista, própria do positivismo, buscando generalizar resultados de investigações empíricas anteriores. As suas observações acerca do conceito de capital social são marcadas pelas características do utilitarismo e do funcionalismo. Também é importante destacar que, em algumas de suas discussões, são consideradas as contradições inerentes ao processo dialético, porém não se pode concluir que essas considerações são predominantes ao longo de suas observações. As contribuições de Fukuyama estão claramente alinhadas ao paradigma funcionalista devido à predominância de princípios do utilitarismo, sistemismo e funcionalismo. Também cabe destacar que Fukuyama realiza uma discussão abrangente, pautada em uma perspectiva histórica e revelando contradições inerentes ao tema, próprias da dialética, embora este último elemento não tenha predominância em suas contribuições.

Sumantra Ghoshal tem uma importância particular para a área da administração por ter articulado o conceito de capital social com teorizações próprias dessa área. As contribuições de Ghoshal possuem um maior alinhamento ao paradigma funcionalista devido à presença de uma série de princípios das correntes que apoiam esse paradigma, como o empirismo, o utilitarismo, o sistemismo e o positivismo. Sobretudo, a discussão de Ghoshal sobre capital social é fortemente marcada pelos princípios do racionalismo.

Portanto, é possível concluir que as abordagens de Bourdieu, Coleman, Putnam, Fukuyama e Ghoshal sobre capital social convergem ao buscarem princípios do utilitarismo nas suas elaborações. Também é possível concluir que as abordagens de Bourdieu, Coleman, Fukuyama e Ghoshal convergem ao buscarem princípios do sistemismo. Da mesma forma, Coleman, Putnam e Fukuyama convergem ao buscarem princípios funcionalistas, enquanto Coleman, Putnam e Ghoshal convergem na busca pelo empirismo. A perspectiva histórica é compartilhada, particularmente, nas abordagens de Putnam e Fukuyama. De maneira singular, a abordagem de Bourdieu apresenta uma intenção desmistificadora e a abordagem de Ghoshal apresenta uma predominância do racionalismo.

Considerando as perspectivas de análise da sociologia, da ciência política e da administração, é possível apontar algumas possíveis implicações particulares na construção de estudos sobre capital social na 
administração. A perspectiva sociológica do capital social é capaz de fornecer subsídios para discussões críticas ou macrossociais, enfatizando análises com os aspectos desmistificadores ou sistêmicos da realidade social. A perspectiva política do capital social é capaz de fornecer subsídio para uma discussão pautada na ideologia de desenvolvimento, enfatizando análises com perspectiva histórica associada às trajetórias institucionais locais, regionais e nacionais. Por sua vez, a perspectiva administrativa do capital social é capaz de fornecer subsídio para uma discussão no nível microssocial, enfatizando análises pautadas na divisão racional das dimensões de uma determinada estrutura social.

De acordo com Chanlat e Séguin (1987), as abordagens de Coleman, Putnam, Fukuyama e Ghoshal podem ser classificadas como desenvolvidas em um paradigma funcionalista, enquanto a abordagem de Bourdieu pode ser posicionada em um paradigma crítico. É importante destacar que apesar da frequente referência nas pesquisas brasileiras aos textos de Bourdieu, não se trata de dizer que os estudos nacionais que fazem referência a esse autor também estejam alinhados ao paradigma crítico. Porém, a questão é que a contribuição de Bourdieu sobre capital social é um marco referencial do tema que é utilizado por outros autores, inclusive pelos demais autores analisados nessa discussão, que se posicionam em um paradigma funcionalista. Portanto, a maioria das referências está alinhada ao paradigma funcionalista, sugerindo que os estudos sobre capital social na administração estejam alinhados a esse paradigma. Para intensificar o debate sobre capital social na administração, é interessante o surgimento de estudos que estejam alinhados ao paradigma crítico, utilizando as contribuições de Loury (1977), Bourdieu (1986) e Lin (1999) como referências.

Essa discussão vem contribuir para o campo dos estudos organizacionais ao jogar luz sobre o cabedal epistemológico de referências frequentes sobre capital social, que é um tema capaz de trazer explicações para a realidade organizacional contemporânea. Para futuras discussões, sugere-se estender a análise da produção científica nacional sobre capital social na administração, destacando os conceitos mais utilizados, os temas relacionados e o alinhamento epistemológico dos estudos. Também sugere-se para os futuros estudos realizar a redução sociológica (GUERREIRO RAMOS, 1996; BERGUE e KLERING, 2010) da epistemologia do capital social na área da administração para o contexto brasileiro.

\section{Referências}

ADLER, P. S.; KWON, S.-W. Social Capital: Prospects for a New Concept. Academy of Management Review, v. 27, n. 1, 2002. p. 17-40.

AUDET, M.; DÉRY, R. La science réfléchie. Quelques empreintes de l'épistémologie des sciences de l'administration. Anthropologie et Sociétés, v. 20, n. 1, p. 103-123, 1996.

BACON, F. Novum Organum: Ou verdadeiras indicações acerca da interpretação da natureza. 2. ed. São Paulo: Abril Cultural, 1979.

BARCELLOS, R. M. R.; DELLAGNELO, E. L. Responsabilidade social corporativa: Uma discussão a respeito da epistemologia subjacente aos conceitos utilizados na área. Revista Eletrônica de Administração REAd, v. 74, n. 1, p. 35-60, 2013.

BENSON, J. K. Les organisations: un point de vue dialectique. In: CHANLAT, J.-F.; SEGUIN, F. L'analyse des organisations: une anthologie sociologique. Tome I. Montreal: Gaëtan-Morin, 1987.

BENTHAM, J. Uma introdução aos princípios da moral e da legislação. 2. ed. São Paulo: Abril Cultural, 1979.

BERGUE, S. T.; KLERING, L. R. A redução sociológica no processo de transposição de tecnologias gerenciais. O\&S Organizações \& Sociedade, v. 17, n. 52, p. 137-155, 2010. 
BLUCKLEY, W. A sociologia e a moderna teoria dos sistemas. São Paulo: Cultrix, 1971.

BOURDIEU, P. Le capital social. Actes de la recherche en sciences socieales, v. 31, p. 2-3, 1980.

BOURDIEU, P. Le trois états du capital culturel. Actes de la recherche en sciences socieales, v. 30, p. 3-6, 1979.

BOURDIEU, P. The forms of capital. In: RICHARDSON, J. G. (Ed.). Handbook of theory and research for the sociology of education. New York: Greenwood Press, 1986.

BURT, R. S. Brokerage and closure: An introduction to social capital. New York: Oxford University Press, 2005.

CAMPOS, A. M. Contribuição para o resgate da relevância do conhecimento para a administração. PHYSIS: Rev. Saúde Coletiva, v. 7, n. 2, p. 105-127, 1997.

CAULKIN, S. Obituary: Sumantra Ghoshal: Management strategy innovator. The Guardian, 8 de março de 2004. Disponível em: <http://www.guardian.co.uk/news/2004/mar/08/guardianobituaries.india>. Acesso em 12 de outubro de 2012.

CHANLAT, J.-F.; SÉGUIN, F. L'analyse des organisations: une anthologie sociologique. Tome I. Montreal: GaëtanMorin, 1987.

CHEVAlliER, J.; LOSCHAK, D. A ciência administrativa. Mem Martins: Europa-America, 1980.

COLEMAN, J. S. Norms as Social Capital. In: RADNITZKY, G.; BERNHOLZ, P. (Eds.). Economic Imperialism. New York: Paragon, 1987.

COLEMAN, J. S. Social Capital in the Creation of Human Capital. American Journal of Sociology, v. 94, n. Supplement: Organizations and Institucions: Sociological and Economic Approaches to the Analysis of Social Structure, p. S95-S120, 1988.

COLEMAN, J. S. Foundations of Social Theory. Cambridge: Harvard University Press, 1990.

DEMO, P. Metodologia científica em ciências sociais. São Paulo: Atlas, 1985.

DESCARTES, R. Discurso do método: meditações: objeções e respostas: as paixões da alma: cartas. Coleção os pensadores. São Paulo: Abril Cultural, 1979.

DORTIER, J. F. Le cercle de Vienne et le nouvel sprit scientifique. Sciences Humaines, hors-série, september 2000.

DUCCI, N. P. C.; TEIXEIRA, R. M. As redes sociais dos empreendedores na formação do capital social: um estudo de casos múltiplos em municípios do norte pioneiro no estado do Paraná. Cadernos EBAPE.BR, v. 9, n. 4, p. 967-997, 2011.

DURKHEIM, E. Da divisão do trabalho social. Coleção os pensadores. São Paulo: Abril Cultural, 1978.

EVANS-PRITCHARD, E. E. Antropologia social. Lisboa: Edições 70, 1972.

FERNANDES, A. S. A. Conselhos municipais: participação, efetividade e institucionalização - a influência do contexto político na dinâmica dos conselhos - os casos de Porto Alegre e Salvador. Cadernos EBAPE.BR, v. 8, n. 3, 2010. p. 438-452.

FOSS, K. et al. The Entrepreneurial Organization of Heterogeneous Capital. Journal of Management Studies, v. 44, n. 7, p. 1165-1186, 2007.

FOSS, N. J. The Continuing relevance of Austrian Capital Theory. The Quarterly Journal of Austrian Economics, v. 15, n. 2, p. 151-171, 2012. 
FOULQUIÉ, P. A dialética. Lisboa: Europa-América, 1978.

FUKUYAMA, F. Social capital and the global economy. Foreign Affairs, v. 74, n. 5, p. 89-103, sept./oct. 1995.

FUKUYAMA, F. Confiança: as virtudes sociais e a criação da prosperidade. Rio de Janeiro: Rocco, 1996.

FUKUYAMA, F. A grande ruptura: a natureza humana e a reconstituição da ordem social. Rio de Janeiro: Rocco, 2000 .

FULKERSON, G. M.; THOMPSON, G. H. The Evolution of a Contested Concept: A Meta-Analysis of Social Capital Definitions and Trends (1988-2006). Sociological Inquiry, v. 78, n. 4, p. 536-557, 2008.

GARCIA, F. C.; BRONZO, M. As bases epistemológicas do pensamento administrativo convencional e a crítica à teoria das organizações. In: Anais do Encontro da Divisão de Estudos Organizacionais da ANPAD - EnEO. 1, ANPAD, Curitiba, 2000.

GUERREIRO RAMOS, A. A redução sociológica. 3. ed. Rio de Janeiro: UFRJ, 1996.

GUERREIRO RAMOS, A. A nova ciência das organizações: uma reconceituação da riqueza das nações. 2. ed. Rio de Janeiro: FGV, 1989.

GURVITCH, G. Dialética e sociologia. São Paulo: Vértice, 1987.

HANIFAN, L. J. The rural school community center. Annals of the American Academy of Political and Social Science, v. 67, n. New Possibilities in Education, p. 130-138, 1916.

HELAL, D. H.; NEVES, J. A. B. Superando a pobreza: o papel do capital social na Região Metropolitana de Belo Horizonte. Cadernos EBAPE.BR, v. 5, n. 2, p. 1-13, 2007.

HUNT, E. K. História do pensamento econômico: uma perspectiva crítica. 5. ed. Rio de Janeiro: Campus, 1985.

JACOBS, J. Morte e vida de grandes cidades. 2. ed. São Paulo: WMF Martins Fontes, 2009.

JAPIASSU, H. Introdução ao pensamento epistemológico. Rio de Janeiro: Francisco Alves, 1991.

LACHMANN, L. M. Capital and its structure. 2. ed. Kansas: Sheed Andrews and McMeel, 1978.

LEFEBVRE, H. Lógica formal. Lógica dialética. Rio de Janeiro: Civilização Brasileira, 1983.

LEWIN, P.; BAETJER, H. The capital-based view of the firm. Review of Austrian Economics, v. 24, n. 4, p. 335-354, 2011.

LIN, N. Building a network theory of social capital. Connections, v. 22, n. 1, p. 28-51, 1999.

LOURY, G. C. A Dynamic Theory of Racial Income Differences. In: WALLACE, P. A.; LAMOND, A. M. (Eds.). Women, Minorities, and Employment Discrimination. Lexington, MA: Lexington Books, 1977. 153-88 p.

MALINOWSKI, B. Uma teoria científica da cultura. Rio de Janeiro: Zahar, 1970.

MARX, K. O capital: crítica da economia política. Os economistas. São Paulo: Abril Cultural, 1984.

NAHAPIET, J.; GHOSHAL, S. Social capital, intellectual capital, and the organizational advantage. Academy of Management Review, v. 23, n. 2, p. 242-266, 1998.

NOHRIA, N.; GHOSHAL, S. The differentiated network: organizing multinational corporations for value creation. San Francisco: Jossey-Bass, 1997. 
PADOVANI, U.; CASTAGNOLA, L. História da filosofia. São Paulo: Melhoramentos, 1990.

PARSONS, T. Sugestões para um tratado sociológico da teoria de organização. In: ETZIONI, A. (Org.), Organizações complexas. São Paulo: Atlas, 1967.

POPPER, K. R. A lógica da investigação científica. Coleção os pensadores. São Paulo: Abril Cultural, 1980.

PORTES, A. Social Capital: Its Origins and Applications in Modern Sociology. Annual Review of Sociology, v. 24 , p. 1-24, 1998.

PUTNAM, R. D. Bowling Alone: The collapse and revival of American community. New York: Simon \& Schuster, 2000.

PUTNAM, R. D. Comunidade e Democracia: a experiência da Itália moderna. 2. ed. Rio de Janeiro: FGV, 2002.

RADCLIFFE-BROWN, A. R. Estrutura e função na sociedade primitiva. Petrópolis: Vozes, 1973.

RÉGIS, H. P.; DIAS, S. M. R. C.; BASTOS, A. V. B. Articulando Cognição, Redes e Capital Social: um estudo entre empresários participantes de incubadoras de empresas. In: Anais do Encontro da ANPAD. 30, ANPAD, Salvador, 2006.

RIGO, A. S.; OLIVEIRA, R. R. Capital social, desenvolvimento local e stakeholders: o caso do projeto Urbe do Sebrae. Cadernos EBAPE.BR, v. 6, n. 2, p. 1-24, 2008.

ROSENWEIG, J.; KAST, F. Organização e administração: um enfoque sistêmico. 2. ed. São Paulo: Pioneira, 1980.

SCHLICK, M. Positivismo e realismo. In: SCHLICK, M.; CARNAP, R. Coletânea de textos. São Paulo: Abril Cultural, 1980.

SELZNICK, P. Fundamentos da teoria de organização. In: ETZIONI, A. (Org.). Organizações complexas. São Paulo: Atlas, 1967.

SERAFIM, M. C.; ANDION, C. Capital espiritual e as relações econômicas: Empreendedorismo em organizações religiosas. Cadernos EBAPE.BR, v. 8, n. 3, p. 564-579, 2010.

SERVA, M. O Surgimento e o desenvolvimento da epistemologia da administração: inferências sobre a contribuição ao aperfeiçoamento da teoria administrativa. RGO Revista Gestão Organizacional, v. 6, n. edição especial, p. 51-64, 2013.

SOUZA-SANTOS, B. Um discurso sobre as ciências na transição para uma ciência pós-moderna. Estudos Avançados, v. 2, n. 2, p. 46-71, 1988.

STANFORD UNIVERSITY. Francis Fukuyama: Biography. Disponível em: 〈http://fukuyama.stanford.edu>. Acesso em 02 de novembro de 2012.

TONINI, H.; MACKE, J. Confiança e capital social para o desenvolvimento de comunidades rurais: o caso da Aprovale. RGSA Revista de Gestão Social e Ambiental, v. 1, n. 3, p. 99-111, 2007.

TSAI, W.; GHOSHAL, S. Social capital and value creation: the role of intrafirm networks. The Academy of Management Journal, v. 41, n. 4, p. 464-476, 1998.

WACQUANT, L. The Sociological Life of Pierre Bourdieu. International Sociology, London, v. 17, n. 4, p. 549-556, 2002. 